\title{
Knock-In Mice Expressing a 15-Lipoxygenating Alox5 Mutant Respond Differently to Experimental Inflammation Than Reported Alox $5^{-1-}$ Mice
}

\author{
Eugenia Marbach-Breitrück ${ }^{1}$, Nadine Rohwer ${ }^{2,3,4,5}$, Carmen Infante-Duarte ${ }^{6}$, Silvina Romero-Suarez ${ }^{6}$, \\ Dominika Labuz ${ }^{7}$, Halina Machelska ${ }^{7}$, Laura Kutzner ${ }^{8}$, Nils Helge Schebb ${ }^{8}$, Michael Rothe ${ }^{9}$, Pallu Reddanna ${ }^{10}$, \\ Karsten H. Weylandt $2,3,4,5$, Lothar H. Wieler ${ }^{11,12}$, Dagmar Heydeck ${ }^{1}$ (D) and Hartmut Kuhn ${ }^{1, *(D)}$
}

1 Department of Biochemistry, Charité-Universitätsmedizin Berlin, Corporate Member of Freie Universität Berlin and Humboldt-Universität zu Berlin, Chariteplatz 1, 10117 Berlin, Germany; eugenia.marbach@yahoo.de (E.M.-B.); dagmar.heydeck@charite.de (D.H.)

2 Division of Medicine, Department of Gastroenterology, Metabolism and Oncology, Ruppin General Hospital, Brandenburg Medical School, Fehrbelliner Straße 38, 16816 Neuruppin, Germany; nadine.rohwer@mhb-fontane.de (N.R.); karsten.weylandt@mhb-fontane.de (K.H.W.)

3 Faculty of Health Sciences, Joint Faculty of the Brandenburg University of Technology Cottbus-Senftenberg, Brandenburg Medical School and University of Potsdam, 14469 Potsdam, Germany

check for updates

Citation: Marbach-Breitrück, E.; Rohwer, N.; Infante-Duarte, C.; Romero-Suarez, S.; Labuz, D.; Machelska, H.; Kutzner, L.; Schebb, N.H.; Rothe, M.; Reddanna, P.; et al. Knock-In Mice Expressing a 15-Lipoxygenating Alox5 Mutant Respond Differently to Experimental Inflammation Than Reported Alox $5^{-/-}$Mice. Metabolites 2021, 11, 698. https://doi.org/10.3390/ metabo11100698

Academic Editor: Helena Idborg

Received: 27 July 2021

Accepted: 7 October 2021

Published: 12 October 2021

Publisher's Note: MDPI stays neutral with regard to jurisdictional claims in published maps and institutional affiliations.

Copyright: () 2021 by the authors. Licensee MDPI, Basel, Switzerland. This article is an open access article distributed under the terms and conditions of the Creative Commons Attribution (CC BY) license (https:// creativecommons.org/licenses/by/ $4.0 /)$.
4 Department of Hepatology, Charité-Universitätsmedizin Berlin, Corporate Member of Freie Universität Berlin and Humboldt-Universität zu Berlin, Gastroenterology and Metabolism, Augustenburger Platz 1, 13353 Berlin, Germany

5 Department of Molecular Toxicology, German Institute of Human Nutrition Potsdam-Rehbruecke, Arthur-Scheunert-Allee 114-116, 14558 Nuthetal, Germany

6 Institute for Medical Immunology, Charité-Universitätsmedizin Berlin, Corporate Member of Freie Universität Berlin and Humboldt-Universität zu Berlin, Augustenburger Platz 1, 13353 Berlin, Germany; carmen.infante@charite.de (C.I.-D.); silvina.romero-suarez@medma.uni-heidelberg.de (S.R.-S.)

7 Department of Experimental Anesthesiology, Charité-Universitätsmedizin Berlin, Corporate Member of Freie Universität Berlin and Humboldt-Universität zu Berlin, Hindenburgdamm 30, 12203 Berlin, Germany; dominika.labuz@charite.de (D.L.); hmachelska@gmail.com (H.M.)

8 Chair of Food Chemistry, Faculty of Mathematics and Natural Sciences, University of Wuppertal, Gaussstraße 20, 42119 Wuppertal, Germany; laura.kutzner@schebb-web.de (L.K.); nils@schebb-web.de (N.H.S.)

9 Lipidomix $\mathrm{GmbH}$, Robert-Rössle-Straße 10, 13125 Berlin, Germany; michael.rothe@lipidomix.de

10 Department of Animal Biology, School of Life Sciences, University of Hyderabad, Gachibowli, Hyderabad 500046, Andhra Pradesh, India; preddanna@gmail.com

11 Robert Koch Institute, Nordufer 20, 13353 Berlin, Germany; WielerLH@rki.de

12 Center of Infection Medicine, Institute of Microbiology and Epizootics, Free University of Berlin, Robert-von-Ostertag-Str. 7-13, 14163 Berlin, Germany

* Correspondence: hartmut.kuehn@charite.de

\begin{abstract}
Arachidonic acid 5-lipoxygenase (ALOX5) is the key enzyme in the biosynthesis of proinflammatory leukotrienes. We recently created knock-in mice (Alox5-KI) which express an arachidonic acid 15-lipoxygenating Alox5 mutant instead of the 5-lipoxygenating wildtype enzyme. These mice were leukotriene deficient but exhibited an elevated linoleic acid oxygenase activity. Here we characterized the polyenoic fatty acid metabolism of these mice in more detail and tested the animals in three different experimental inflammation models. In experimental autoimmune encephalomyelitis (EAE), Alox5-KI mice displayed an earlier disease onset and a significantly higher cumulative incidence rate than wildtype controls but the clinical score kinetics were not significantly different. In dextran sodium sulfate-induced colitis (DSS) and in the chronic constriction nerve injury model (CCI), Alox5-KI mice performed like wildtype controls with similar genetic background. These results were somewhat surprising since in previous loss-of-function studies targeting leukotriene biosynthesis (Alox $5^{-/-}$mice, inhibitor studies), more severe inflammatory symptoms were observed in the EAE model but the degree of inflammation in DSS colitis was attenuated. Taken together, our data indicate that these mutant Alox5-KI mice respond differently in two models of experimental inflammation than $A l o x 5^{-1-}$ animals tested previously in similar experimental setups.
\end{abstract}


Keywords: eicosanoids; lipoxygenase; inflammation; pain; leukotrienes; resolvins

\section{Introduction}

The arachidonic acid lipoxygenases (ALOX-isoforms) are lipid-peroxidizing enzymes [1,2], which have been implicated in the biosynthesis of pro- and anti-inflammatory mediators [3,4]. The human genome involves six functional ALOX genes (ALOX15, ALOX15B, $A L O X 12, A L O X 12 B, A L O X E 3, A L O X 5)$, most of which are localized in the joint ALOX-gene cluster on chromosome 17 [5]. In contrast, the $A L O X 5$ gene was mapped to chromosome 10. In the mouse genome a single ortholog exists for each human gene, but in addition a functional Aloxe12 gene is present in the Alox gene cluster on mouse chromosome 17 [5].

Mammalian ALOX5 orthologs are essential for the biosynthesis of pro-inflammatory leukotrienes [3], and the first ALOX5 ortholog was discovered in leukocytes of different species [6]. ALOX5 genes are present in the genome of most mammals, but have also been described in lower vertebrates, invertebrates and metazoa $[7,8]$. ALOX5 orthologs catalyze the conversion of arachidonic acid to 5,6-epoxyleukotriene $\left(\mathrm{LTA}_{4}\right)$. This unstable intermediate is further hydrolyzed by $\mathrm{LTA}_{4}$ hydrolase [9] to leukotriene $\mathrm{B}_{4}\left(\mathrm{LTB}_{4}\right)$ or is alternatively converted by $\mathrm{LTC}_{4}$ synthase [10] to leukotriene $\mathrm{C}_{4}\left(\mathrm{LTC}_{4}\right)$. $\mathrm{LTB}_{4}$ is a strong pro-inflammatory mediator, which activates neutrophils but also induces chemokinesis of inflammatory cells [11,12]. $\mathrm{LTC}_{4}$ and $\mathrm{LTD}_{4}$ induce sustained bronchoconstriction, bronchial mucus secretion and increased permeability of the blood vessel wall [13]. Currently, cysteinyl leukotriene receptor antagonists [14] and a specific ALOX5 inhibitor [15] are available for prescription for the treatment of bronchial asthma. Alox5-deficient mice were protected from inflammation in different animal disease models [16], and administration of a lipid-rich Western diet to these animals induced the formation of aortic aneurisms [17].

ALOX15 was first discovered in rabbit reticulocytes [18]. The enzyme is expressed as cytosolic protein and was purified to homogeneity in mg amounts [19]. The properties of rabbit ALOX15 [19] and of other mammalian ALOX15 orthologs [20-22] have been characterized and the enzymes exhibit two catalytic peculiarities: (i) They show dual reaction specificity with arachidonic acid [23,24]; (ii) they oxygenate esterified polyenoic fatty acids even if these substrates are present in ester lipids of lipoproteins and biomembranes [18]. Alox $15^{-/-}$mice are viable and grow normally [25] but they exhibit significantly reduced erythrocyte counts and subtle reticulocytosis [26]. In different murine inflammation models, Alox15 $15^{-/}$mice develop more [27] or less [28] intense inflammatory symptoms, and thus ALOX15 may play a regulatory role in inflammation. The anti-inflammatory activity of ALOX15 has been related to the involvement of this enzyme in the biosynthesis of pro-resolving mediators [29] or in the activation cascade of the peroxisome proliferation activating receptor gamma (PPAR $\gamma)[30]$.

The inverse biological functions of ALOX5 (pro-inflammatory) and ALOX15 (proresolving) are directly related to the reaction specificity of the two enzymes. Arachidonic acid 5-lipoxygenation is essential for the biosynthesis of pro-inflammatory leukotrienes [1], whereas arachidonic acid 15-lipoxygenation has been implicated in the biosynthesis of specialized pro-resolving mediators [4,29]. If one could alter the reaction specificity of ALOX5 from arachidonic acid 5- to arachidonic acid 15-lipoxygenation, it should be possible to transform the pro-inflammatory ALOX5 to a pro-resolving enzyme. It should be stressed at this point that the idea that mammalian ALOX5 orthologs are pro-inflammatory enzymes and that ALOX15 orthologs are anti-inflammatory is rather simplistic. For instance, the biosynthesis of specialized pro-resolving mediators (SPMs) may involve both ALOX5 and ALOX15 orthologs $[4,31]$. Moreover, there are ALOX5-dependent and ALOX5-independent biosynthetic pathways for the formation of SPMs [4,31]. Because of this complexity, it is impossible to predict the impact of selective functional modification of the ALOX5 gene on the biosynthetic capacity of inflammatory cells to produce SPMs. 
Several years ago, we reported that combined mutations of the triad determinants of human ALOX5 (Phe359Trp + Ala424Ile + Asn425Met + Ala603Ile) induced such a switch in the reaction specificity [32], and similar specificity alterations were later observed for mouse Alox5 [33]. To explore whether this mutagenesis concept also works in vivo, we recently created knock-in mice, which express the Alox5 Phe359Trp + Ala424Ile + Asn425Met triple mutant instead of the wildtype enzyme [34]. These animals exhibit defective leukotriene biosynthesis [34], but it has not been explored how they perform under inflammatory conditions.

To fill this gap, we tested our Alox5 knock-in (Alox5-KI) mice in three different animal disease models associated with inflammation. We found that in the experimental autoimmune encephalomyelitis (EAE) model and in the dextran sodium sulfate induced colitis (DSS) model, Alox5-KI mice showed different responses than other leukotriene-deficient animals explored in the literature $[35,36]$.

\section{Results}

\subsection{Functional Characterization of Alox5 Knock-in Mice (Alox5-KI)}

In our Alox5-KI mice, the Alox5 gene was modified by site-directed mutagenesis of the triad determinants to reach two independent goals: i) Inactivation of the arachidonic acid 5-lipoxygenase activity and the leukotriene synthase activity of Alox5. As the first consequence of this alteration, we expected that the Alox5-KI mice might perform like Alox $5^{-/-}$mice in animal disease models, in which leukotrienes may play a major patho-physiological role. ii) Upregulation of the arachidonic acid 15-lipoxygenating activity. As a second consequence of this alteration, we expected an improved formation of 13-hydroxy-linoleic acid (13-HODE) from linoleic acid and 15-hydroxy arachidonic acid (HETE) from arachidonic acid). The second consequence may overlay the biological effects induced by leukotriene deficiency.

Before using these animals in the different inflammatory disease models, we first characterized the functional alterations induced by this genetic manipulation. With some exceptions, ALOX isoforms are either expressed in myeloid cells (ALOX15, ALOX15B, ALOX12, ALOX5) or in the skin (ALOX12B, ALOXE3, ALOXE12). Since we were mainly interested in the myeloid ALOX isoforms, we selected peritoneal lavage cells and bone marrow cells as targets for the functional characterization studies. As solid organs, peritoneal lavage and bone marrow cells are heterogenous mixtures of different cell types, but abundant expression of different ALOX-isoforms in these cell populations is well documented. In the first step, we quantified by qRT-PCR the mRNA expression levels of all 7 mouse Alox-isoforms in these cells of wildtype mice and found (Figure 1A) that Alox 15 mRNA is dominantly present in peritoneal lavage cells. Alox 5 mRNA was detected in much smaller amounts, but the mRNAs of the other isoforms were virtually absent. In bone marrow cells (Figure 1B), the situation was more complex. Here we observed that Alox12 mRNA was most abundant, followed by the mRNAs of Alox5, Alox15 and Alox15b. The mRNAs of epidermal Alox isoforms (Alox12b, Aloxe3, Aloxe12) were only detected at very low steady state mRNA concentrations.

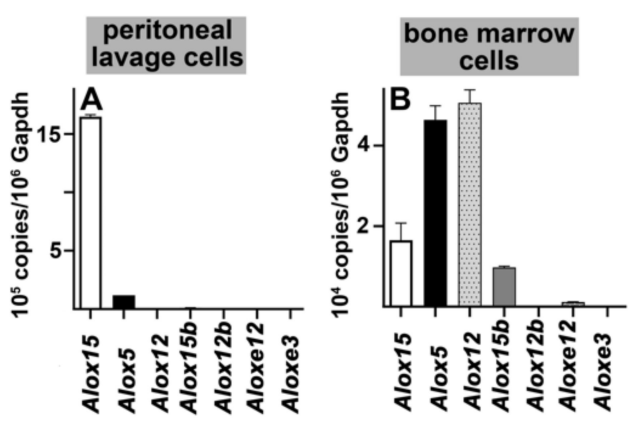

Figure 1. Expression of Alox mRNAs in peritoneal lavage and bone marrow cells of wildtype mice. 
Cells were prepared from wildtype mice as described in the Materials and Methods section. Total RNA was extracted, reversely transcribed and the different Alox mRNA species were quantified by qRT-PCR using external amplification standards for each target mRNA (mRNAs of different Alox paralogs) and the reference mRNA (Gapdh). (A) qRT-PCR of mouse Alox mRNAs of wildtype peritoneal lavage cells. For this experiment the RNA of the cell preparation obtained from four different animals $(n=4)$ was pooled and three independent PCR runs were carried out. (B) qRT-PCR of mouse Alox mRNAs of wildtype bone marrow cells. For this experiment, three independent PCR runs were carried out with each RNA pool $(n=4)$.

In a previous study, the expression levels of other Alox-isoforms were different when Alox5-KI mice were compared with corresponding wildtype controls [34]. In fact, comparison of the steady state concentrations of the mRNAs of Alox15 and Alox12 in bone marrow cells of mice did not reveal significant differences between the two genotypes. Thus, our genetic manipulation of the Alox 5 gene does not induce a compensatory upregulation in the expression of other Alox isoforms.

To provide additional evidence for the leukotriene deficiency of our Alox5-KI mice, we carried out ex vivo activity assays using peripheral blood as an enzyme source. For this purpose, heparinized blood was drawn from Alox5-KI mice and corresponding outbred wildtype control animals (WT) and incubated for $30 \mathrm{~min}$ in the presence of $50 \mu \mathrm{M}$ calcium ionophore A23187. Blood cells were spun down and the profiles of relevant eicosanoids in the blood plasma were quantified by LC-MS/MS (see Materials and Methods). From Figure 2, it can be seen that after ionophore stimulation significant amounts of leukotriene $\mathrm{B}_{4}\left(\mathrm{LTB}_{4}\right)$ were present in the blood plasma of WT animals. In contrast, no $\mathrm{LTB}_{4}$ could be detected when the blood plasma of Alox5-KI mice was analyzed. These data indicate that our Alox5-KI mice are leukotriene deficient. Simultaneously, we analyzed the plasma levels of 5-HETE and found significantly smaller quantities of this eicosanoid in the blood plasma of Alox5-KI mice (Figure 2) when compared with WT controls. Since 5-HETE can also be formed via ALOX5-independent pathways, it is plausible that we did not observe complete abolishment of 5-HETE formation. Our knock-in strategy converted the mouse Alox5 to an arachidonic acid 15-lipoxygenating enzyme and thus it was expected that the 15-HETE levels in the Alox5-KI mice should be elevated. Unfortunately, in our lipidomic analyses we did not find increased 15-HETE levels in the plasma lipids (Figure 2). The most plausible explanation for these data is that the amounts of 15-HETE formed by the mutant Alox5 are not high enough to increase the systemic 15-HETE plasma levels. Finally, we quantified the plasma levels of other HETE-isomers (12-HETE, 9-HETE, 20-HETE) but did not observe significant differences between Alox5-KI mice and wildtype controls.

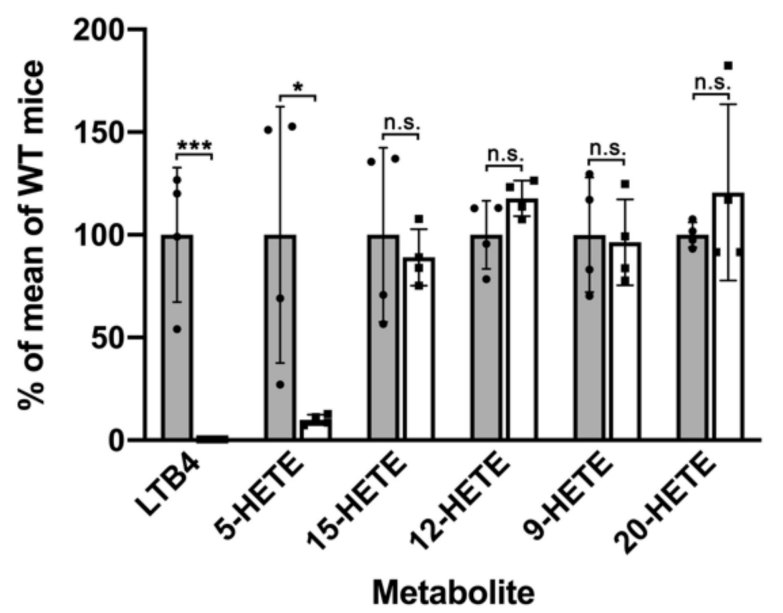

Figure 2. Alox5 ex vivo activity assays using whole blood. Alox5-KI mice and corresponding outbred wildtype controls ( $n=4$ of each genotype) were sacrificed under anesthesia and heparinized blood 
was drawn. Whole blood was incubated for $30 \mathrm{~min}$ at $37^{\circ} \mathrm{C}$ with $50 \mu \mathrm{M}$ calcium ionophoreA23187, cells were spun down and eicosanoid profiles were quantified by LC-MS/MS, as described in the Materials and Methods. For each product, the mean of metabolite formation of wildtype mice was set at $100 \%$ and product formation of each individual of either genotype was normalized to this value. Gray columns show wildtype mice, white columns show Alox5-KI mice. genotype was normalized to this value. Gray columns show wildtype mice, white columns show Alox5-KI mice. Dots indicate the individual values for wildtype mice, square indicate the individual values for Alox5-KI mice. Statistical analyses comparing Alox5-KI mice with wildtype animals were carried out with the two-sided Students $t$-test and the levels of statistical significance are indicated by asterixis $\left.{ }^{*}\right) .{ }^{*} p<0.05,{ }^{* * *} p<0.001 ;$ n.s. indicates no significant differences between the two genotypes. Data are expressed as means $\pm \mathrm{SEM}, n=4$ for each genotype.

Since the Alox5 gene in mice is expressed at high levels in peritoneal lavage cells and in bone marrow cells (Figure 1A,B), we carried out comparative ex vivo activity assays with these cell types prepared from Alox5-KI mice and outbred wildtype controls. For these experiments, the activity assay was optimized for ALOX5 measurements (addition of ionophore A23187) and we added ATP, EDTA, $\mathrm{Ca}^{2+}$ and phosphatidylcholine to the assay mixture. To test the chirality of the major reaction products we employed NP/CP-HPLC with UV-detection as an analytical method. Under these conditions, peritoneal lavage cells of wildtype controls produce $12 \mathrm{~S}$-HETE as major product, but smaller amounts of 15S-HETE and 5S-HETE were also detected (Figure 3A).
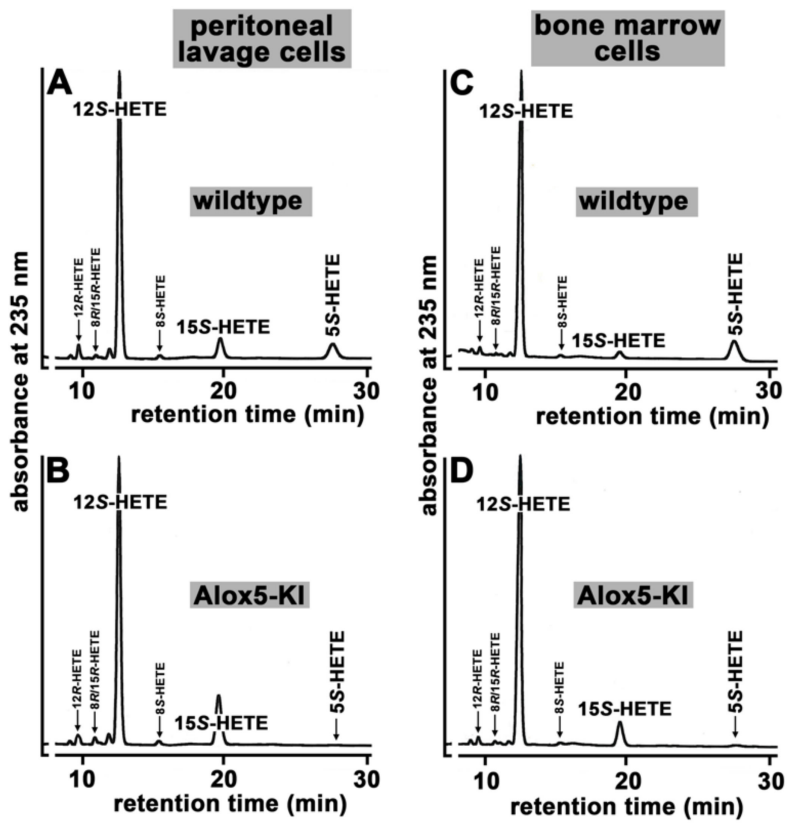

Figure 3. Analysis of the Alox products formed during ex vivo activity assays of peritoneal lavage cells and bone marrow cells of Alox5-KI and wildtype mice. Cells were prepared and ex vivo activity assays were carried out (see Materials and Methods). The conjugated dienes formed during the 15 min incubation period were prepared by RP-HPLC and further analyzed by NP/CP-HPLC (see Materials and Methods). Each chromatogram was scaled for the 12S-HETE peak. Four independent individuals $(n=4)$ were analyzed for each genotype. Representative partial chromatograms are shown, and statistical evaluation of the product patterns is given in Table 1. (A) Wildtype peritoneal lavage cells. (B) Peritoneal lavage cells prepared from Alox5-KI mice. (C) Wildtype bone marrow cells. (D) Bone marrow cells prepared from Alox5-KI mice. 
Table 1. Composition of the major oxygenation products formed during the ex vivo activity assays using different cell preparations from Alox5-KI mice and wildtype controls. Cell preparation, activity assays and RP-HPLC analyses were carried out as described in the legend to Figure 2. The sum of the major oxygenation products was set at $100 \%$ and the relative shares of 15-HETE, 12-HETE and 5-HETE were calculated. Four different animals $(n=4)$ were analyzed for each genotype. To quantify the extent of product formation we subtracted the sizes of the chromatographic peaks (area units) of the no-cell control incubations from the corresponding peak of the cell incubations. In some cases, we found that the 5-HETE levels in the cell incubations were smaller than those in the no-cell control incubations. In these cases, we set the differences to $0 .{ }^{*}$ Comparison (two-sided $t$-test) of the relative shares of each product (12S-HETE, 15S-HETE, 5S-HETE) between Alox5-KI animals and wildtype controls revealed highly significant $(p<0.01)$ differences. \# The difference in $12 S$-HETE formation by peritoneal lavage cells $(84.1 \pm 2.9 \%$ 12S-HETE formation for wildtype cells vs. $82.4 \pm 2.4 \% 12 S$-HETE formation for Alox5-KI cells, $p=0.316$ ) did not reach the level of statistical significance.

\begin{tabular}{ccccc}
\hline \multirow{2}{*}{ Cell Type } & Genotype & \multicolumn{3}{c}{ Product (\%) } \\
\cline { 3 - 5 } & & 5S-HETE & 12S-HETE & 15S-HETE \\
\hline Peritoneal & WT & $7.8 \pm 2.7$ & $84.1 \pm 2.9$ & $8.1 \pm 0.4$ \\
lavage cells & Alox5-KI & $0^{*}$ & $82.4 \pm 2.4^{*}$ & $18.0 \pm 2.4^{*}$ \\
\hline Bone marrow & WT & $12.0 \pm 1.4$ & $85.8 \pm 1.8$ & $2.2 \pm 0.5$ \\
cells & Alox5-KI & $0^{*}$ & $89.7 \pm 0.4^{*}$ & $10.3 \pm 0.4^{*}$ \\
\hline
\end{tabular}

When peritoneal lavage cells of Alox5-KI mice (Figure 3B) were used, the relative share of 15S-HETE formation was significantly elevated $(8.1 \pm 0.4 \%$ for wildtype cells vs. $18.0 \pm 2.4 \%$ for Alox5-KI cells, $p<0.001$, two-sided $t$-test) but $5 S$-HETE formation was almost completely abolished (Figure 3B, Table 1 ). When wildtype bone marrow cells were employed (Figure 3C), 12S-HETE was also the major arachidonic acid (AA) oxygenation product. As with peritoneal lavage cells, small amounts of 5S- and 15S-HETE were also produced and the relative shares of these Alox products are quantified in Table 1. As expected, corresponding cells of Alox5-KI mice did not produce major amounts of 5S-HETE (Figure 3D). On the other hand (Figure 3D), the relative share of 15S-HETE formation increased five-fold ( $2.2 \pm 0.5 \%$ for wildtype bone marrow cells vs. $10.3 \pm 0.4 \%$ for Alox $5-\mathrm{KI}$ bone marrow cells, $p<0.001$, two-sided $t$-test). These alterations in the product pattern could be predicted from our genetic manipulation. It should be stressed at this point that trace amounts of 5-HETE (minor peaks in Figure 3B,D) were also detected in the product mixture formed by bone marrow cells and peritoneal lavage cells of Alox5-KI mice. Such trace amounts were detected in the no-cell control incubations since HETE isomers were present in small amounts in the arachidonic acid solution we used as substrate for the ex vivo activity assays. Thus, the very small amounts of 5-HETE detected in the incubation samples most probably originate from the impurities of the arachidonic acid solution used as substrate for the ex vivo activity assays but not from the residual AA 5-lipoxygenating activity of the mutated Alox5.

To explore whether bone marrow cells of Alox5-KI mice also exhibit a compromised leukotriene synthesizing capacity using endogenous substrate, we stimulated these cells ex vivo with calcium ionophore and analyzed the formation of leukotriene $\mathrm{B}_{4}, 5$-HETE and 15-HETE using an LC-MS/MS based method [37]. Wildtype bone marrow cells (Figure $4 \mathrm{~A}$ ) produced significant amounts of $\mathrm{LTB}_{4}$. As expected, when the activity assay was carried out in the presence of $10 \mu \mathrm{M}$ of the specific ALOX5 inhibitor zileuton [15,38], $\mathrm{LTB}_{4}$ formation was completely abolished (Figure S1). Moreover, Alox5-KI bone marrow cells did not produce $\mathrm{LTB}_{4}$ (Figure 4B). Next, we analyzed the formation of 5-HETE in this ex vivo activity assay and obtained identical results. Large amounts of 5-HETE were formed by wildtype bone marrow cells (Figure 4C) but only traces of this metabolite were detected when Alox5-KI bone marrow cells were employed (Figure 4D). These trace amounts of 5-HETE most likely originate from non-enzymatic lipid peroxidation of the liberated arachidonic acid. When cells are stimulated with calcium ionophore, arachidonic 
acid is released from the cellular membranes and most of this endogenous substrate is oxygenated via the Alox5 pathway. However, small amounts of the liberated substrate may undergo Alox5-independent lipid peroxidation and this share may even be augmented when Alox5-dependent 5-HETE formation is prevented.

Finally, we explored the formation of 15-HETE from endogenous substrates. Here we found that small amounts of this metabolite were formed by wildtype bone marrow cells (Figure 4E). However, Alox5-KI bone marrow cells produced more than twice as much 15-HETE (Figure 4F). When the activity assays were carried out in the presence of $10 \mu \mathrm{M}$ zileuton, 15-HETE formation was reduced to near wildtype levels (Figure S2). The most plausible explanation for these results is that the mutant Alox 5 is responsible for the increased 15-HETE synthesizing capacity of Alox5-KI bone marrow cells.
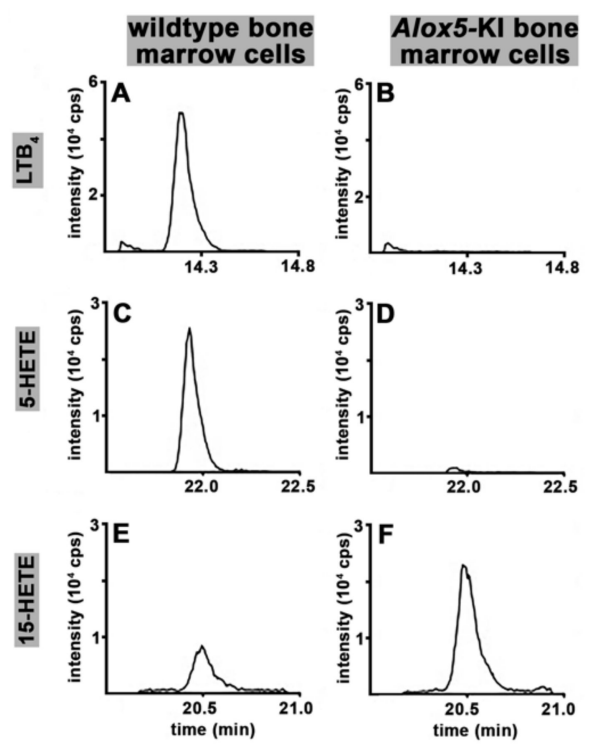

Figure 4. Ex vivo Alox activity assays of bone marrow cells prepared from Alox5-KI mice and corresponding wildtype controls using endogenous substrates. Pooled bone marrow cells of either Alox5-KI mice ( $n=5$; panels $\mathbf{B}, \mathbf{D}$ and $\mathbf{F}$ ) or WT-mice ( $n=3$, panels $\mathbf{A}, \mathbf{C}$ and $\mathbf{E})$ were used. For each assay $2 \times 10^{7}$ cells were reconstituted in $0.5 \mathrm{~mL}$ PBS and were incubated at room temperature in the presence of $5 \mu \mathrm{M}$ calcium ionophore A23187 for $5 \mathrm{~min}$. Total lipids were extracted (ethyl acetate), solvent was evaporated, the remaining lipids were reconstituted in $50 \mu \mathrm{L}$ methanol and analyzed for $\mathrm{LTB}_{4}$ (panels A,B), 5-HETE (panels C,D) and 15-HETE (panels E,F) by LC-MS/MS. Chromatographic separation of lipid extracts was carried out using a Zorbax Eclipse Plus C18 RP-column (Agilent, Waldbronn, Germany) and for MS/MS detection the QTRAP instrument (Sciex, Darmstadt, Germany) was operated in negative electrospray ionisation mode. Shown are SRM traces of cell extracts for $\mathrm{LTB}_{4}(m / z 335.2 \rightarrow 195.1), 5$-HETE $(m / z 319.2 \rightarrow 115.2)$ and 15 -HETE $(m / z 319.2 \rightarrow 219.2)$.

\subsection{Alox5-KI Mice Show Earlier Disease Onset and Higher Cumulative Incidence Rates Than Wildtype Animals in the EAE Model}

The EAE model is a frequently employed murine system to explore the pathophysiological mechanisms of human demyelinating diseases [39], and several inhibitors of the ALOX pathway attenuated the severity of clinical symptoms in this model [40-42]. Moreover, microarray analyses identified ALOX5 as a component of inflammatory brain lesions in human multiple sclerosis and in the EAE mouse model [43]. These data suggested that leukotriene deficiency should lead to attenuated neurological symptoms. In contrast, the symptoms were exacerbated in Alox $5^{-1-}$ mice [35]. In our Alox5-KI mice, two principle functional alterations were combined: (i) Lack of leukotriene biosynthesis, which should lead to reduction of the inflammatory symptoms [16], (ii) augmented capacity for the formation of 15-HETE and 13-HODE, which may activate PPARgamma signaling and 
may suppress inflammation [30]. Thus, based on these previous experimental data it was impossible to predict how the Alox5-KI mice might perform in the EAE model.

To answer this question, we induced a mild form of EAE in Alox5-KI mice and wildtype controls with identical genetic backgrounds and monitored the neurological symptoms over a time period of 22 days. As intended, under our experimental conditions the incidence of clinically manifested EAE was rather low in wildtype mice since seven out of eight animals did not develop neurological abnormalities (Figure 5A). On the other hand, five of the eight Alox5-KI mice showed neurological defects. In fact, the cumulative incidence rate of Alox5-KI mice was significantly $(p=0.037)$ higher than that of the wildtype controls (Figure 5A). Next, we quantified the EAE scores for all mice and evaluated these data statistically. Here we found (Figure 5B) that in wildtype mice only a minor increase in the EAE score was observed. In contrast, Alox5-KI mice developed more pronounced disease symptoms and a biphasic time course became evident. For these mice, the mean EAE scores strongly increased between days 13 and 16, but at day 18 the scores declined again. This attenuation was related to the partial recovery of two animals from their neurological symptoms. However, at later time points these animals became sick again, which contributed to the further raise of the mean EAE score at later time points. It should be stressed at this point that despite the biphasic disease kinetics, the means of the EAE scores of the Alox5-KI mice were always higher than those of the wildtype animals during the entire time course of the experiment. However, when we compared the two EAE score kinetics using the mixed ANOVA test we did not observe significant differences between the two genotypes. Moreover, when we compared the EAE scores for the two genotypes at each time point of the disease we never observed significant differences. Thus, in vivo Phe359Trp + Ala424Ile + Asn425Met triple mutation of the Alox5 gene does not significantly alter the responsiveness of mice in the EAE model, although a trend for an increased responsiveness was observed. Finally, we quantified different lymphocyte populations in the peripheral blood of wildtype mice and Alox5-KI animals at the end of the experimental protocol (Figure S3). However, we did not detect significant differences between the two genotypes ( $n=3$ per group).
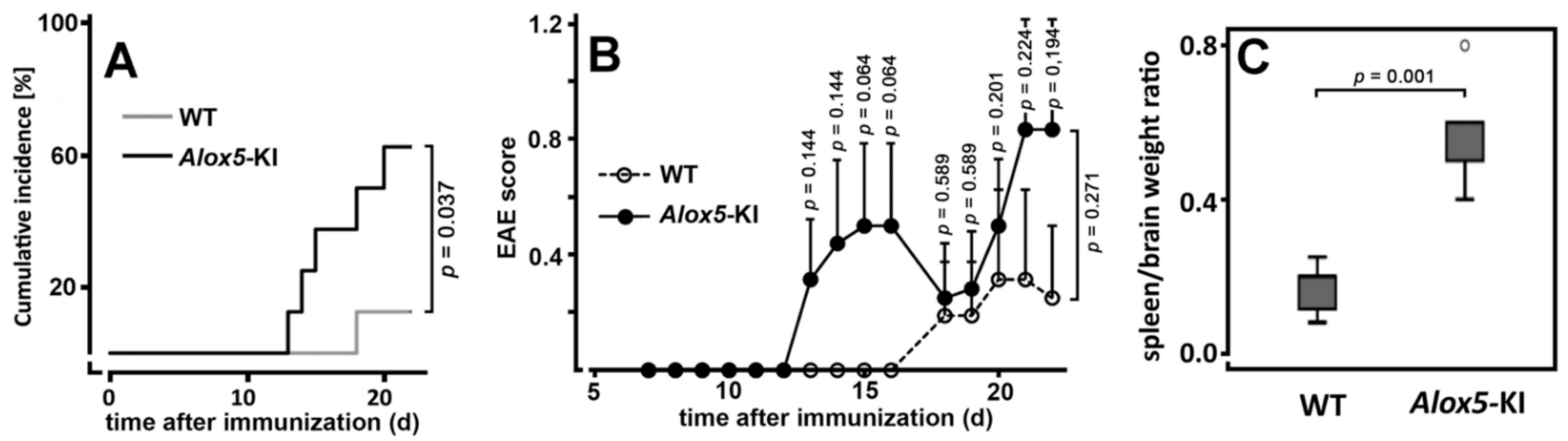

Figure 5. Comparison of Alox5-KI and wildtype mice in the EAE inflammation model. Alox5-KI mice and wildtype controls ( $n=8$ in each group) were taken through the experimental protocol (see Materials and Methods). The clinical EAE scores were determined at the time points indicated. At the end of the experiment the animals were sacrificed at day 22 of the experimental protocol. Data were statistically evaluated using Mann-Whitney U-Test and the mixed ANOVA approach was used to compare the EAE score kinetics of the two genotypes over time. Cumulative incidence was statistically analyzed by Log-Rank test. (A) Onset of disease as indicated by the first appearance of neurological symptoms. (B) EAE score kinetics. Data are means \pm SEM. (C) Relative spleen weight vs. brain weight ratios of the two genotypes $(n=8$ in each experimental group) at the end of the experimental protocol (day 22).

When we sacrificed the animals at the end of the experiments, we observed that the spleens of the Alox5-KI mice were enlarged. When we normalized the spleen weight to the brain weight of each animal (calculation of the spleen weight/brain weight ratios), 
we found that this ratio was significantly higher in Alox5-KI mice when compared with wildtype controls (Figure 5C). It remains unclear for the moment why the Alox5-KI mice develop splenomegaly when taken through this experimental protocol.

Taken together, these data indicated that Alox5-KI mice do not behave like Alox $5^{-/-}$ mice [35] in the EAE model despite the fact that both types of animals were unable to biosynthesize leukotrienes. Thus, the second functional consequence of our genetic manipulation (augmented 15-HETE and 13-HODE formation) may play a modulating role in this animal model of inflammation (see Discussion).

\subsection{Alox5-KI Mice Are Not Protected from Inflammation in the DSS Colitis Model}

The DSS colitis is a frequently employed animal disease model mirroring the pathophysiology of human inflammatory bowel diseases [44]. Previous experiments with the clinically used ALOX5 inhibitor zileuton suggested that inactivation of endogenous leukotriene biosynthesis attenuated the inflammatory symptoms in different animal colitis models [36,45].

When we induced DSS colitis in our Alox5-KI mice and wildtype controls we only observed a minor difference between the two genotypes. Using the relative loss in body weight as major clinical readout parameter, we found that at most time points the means of Alox5-KI were higher than those of wildtype controls (Figure 6A,C). However, these differences did not reach the level of statistical significance at most time points (MannWhitney U-test). Comparing the complete body weight kinetics for either female or male individuals (mixed ANOVA), we did not observe significant differences. Finally, we quantified the colon lengths at the end of the experiment as independent readout parameter for colitis severity. DSS-induced colitis leads to colon shrinkage and the degree of colon shortening mirrors the severity of the disease [44]. When we compared the average colon length of DSS-treated wildtype mice with that of Alox5-KI animals we observed a significant difference $(p=0.008)$ for female individuals (Figure 6B). For males (Figure 6D) we also observed colon shrinkage, but the difference between the two genotypes did not reach the level of statistical significance $(p=0.103)$. At the end of the experiment, we quantified the disease activity index (DAI) as the third clinical parameter of colitis severity. Here, we did not observe significant differences for males ( $p>0.940$, Mann-Whitney U-test) but determined significantly $(p=0.021)$ lower DAI values in female Alox5-KI mice (Figure S4).
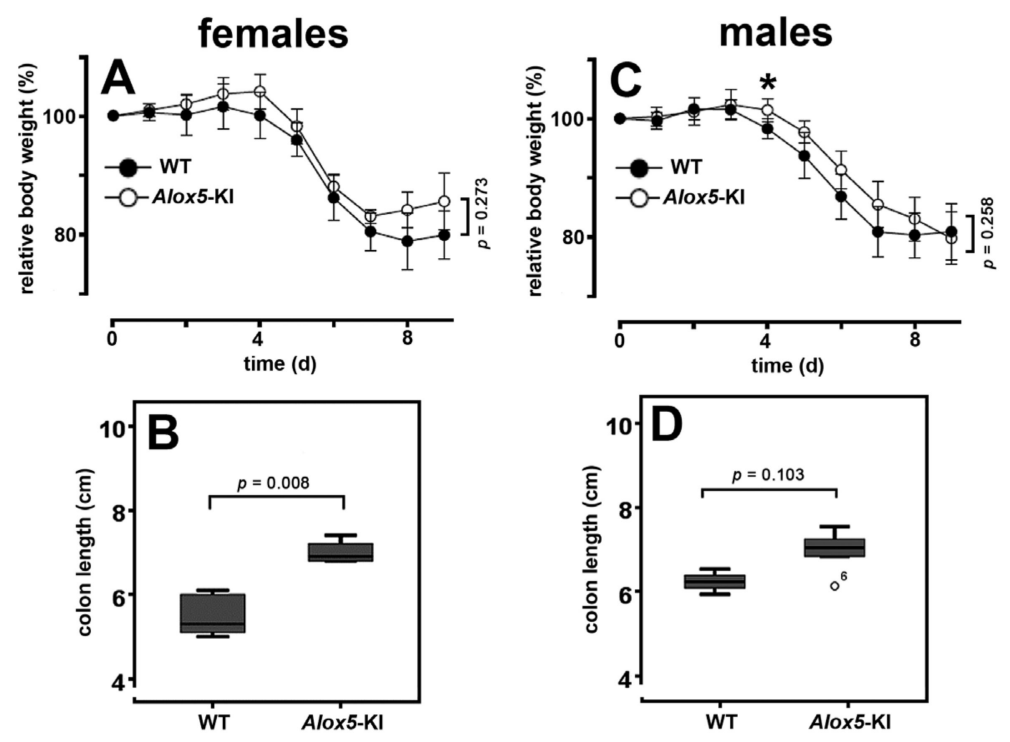

Figure 6. Comparison of Alox5-KI mice and wildtype controls in the DSS colitis model. Alox5-KI mice ( 5 males, 5 females) and outbred wildtype controls ( 5 males, 5 females) were taken through the 
experimental protocol (see Materials and Methods), and we determined two major clinical readout parameters (body weight, colon length). (A,C) Kinetics of the relative weight loss that were calculated as percentage of the body weight at the time of measurement related to the body weight of the corresponding individual before the onset of DSS treatment. At each time point data were statistically evaluated using the Mann-Whitney U-Test and mixed ANOVA approach was used to compare weight loss kinetics of the two genotypes over time. ${ }^{*}$ means there are no significant differences. Data are expressed as means \pm SEM. (B,D) Colon lengths at the end of the experimental protocol. After the animals were sacrificed at the end of the experimental protocol (day 9), the colons were prepared and their lengths were determined.

Taken together, our results suggest no significant differences in the responsiveness of male Alox5-KI mice and corresponding wildtype controls in the DSS colitis model, when the body weight loss was used as a clinical readout parameter. For female Alox5-KI mice, we observed a subtle but significantly lower colon shrinkage and significantly reduced DAI values. The limited protective effect we observed for our Alox5-KI mice in the DSS colitis model was somewhat surprising since the ALOX5 inhibitor zileuton protected animals in different models of inflammatory bowel disease [36,45]. A possible mechanistic explanation for this unexpected outcome is given in the discussion.

\subsection{Alox5-KI Does Not Alter Mechanical and Heat Sensitivity in the Chronic Constriction Nerve Injury Model (CCI)}

Pain is one of the five canonical symptoms of inflammation and ALOX isoforms have been implicated in the development of inflammatory pain [46-48]. ALOX inhibitors exhibited analgesic effects in different animal pain models such as somatic inflammatory pain $[49,50]$, as well as back and neuropathic pain $[36,51]$.

In this study, we employed the CCI neuropathic pain model in which constriction of the sciatic nerve induces neuro-inflammation in the nerve and in the spinal cord, which leads to mechanical and heat hypersensitivity [52-55]. We found that both Alox5-KI and wildtype mice developed comparable CCI-triggered mechanical (manifested by decreased paw withdrawal thresholds assessed in the von Frey test) and heat hypersensitivity (manifested by shorter paw withdrawal latencies assessed by the Hargreaves test) in paws innervated by the injured nerve compared to the thresholds and latencies before CCI. Both forms of hypersensitivity appeared on day 1 of the experimental protocol and lasted until day 21 following CCI. There were no significant differences between the two genotypes when the experimental raw data were evaluated by one-way ANOVA (Figure 7A,C). We did not observe significant differences in the paws contralateral to the CCI in any test and genotype (Figure 7B,D). Taken together, these data suggests that our genetic manipulation of the Alox 5 gene does not modify the pain response in the CCI model.
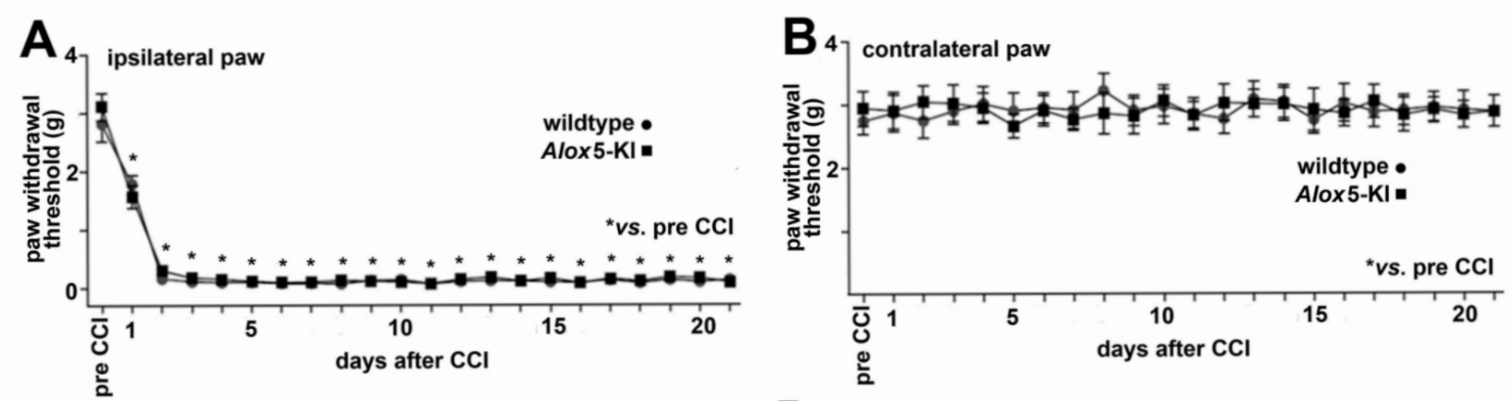

Figure 7. Cont. 

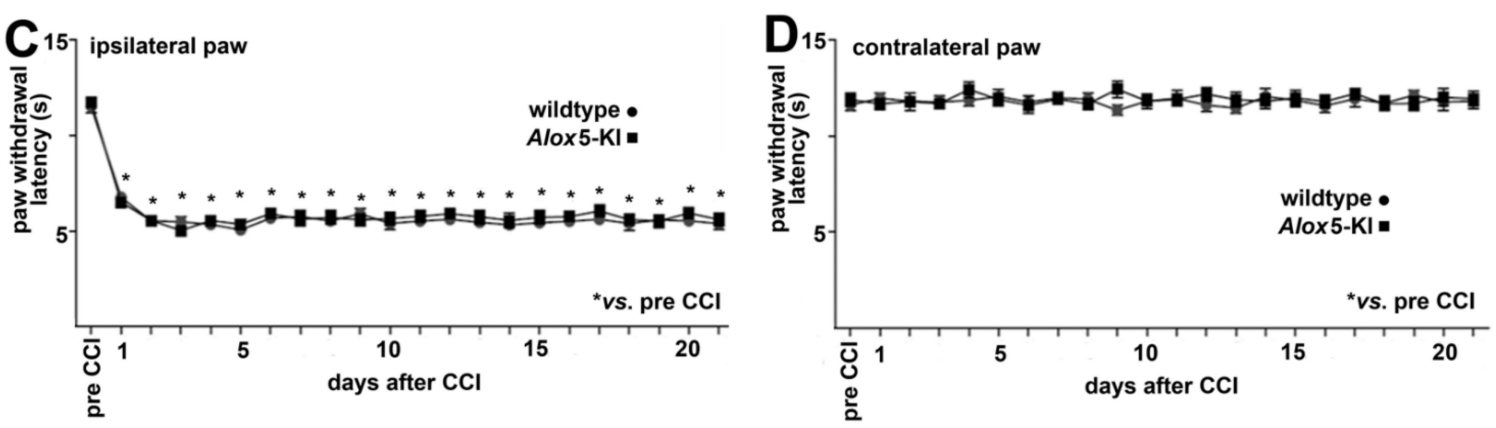

Figure 7. Comparison of Alox5-KI and wildtype mice in the CCI model of neuropathic pain. Mechanical sensitivity assessed by the von Frey test in paws ipsilateral (A) and contralateral (B) to the CCI. The decrease in the paw withdrawal threshold indicates mechanical hypersensitivity. Heat sensitivity assessed by the Hargreaves test in paws ipsilateral (C) and contralateral (D) to the CCI. The decrease in the paw withdrawal latency indicates heat hypersensitivity. ${ }^{*} p<0.001$ vs. values before CCI induction (pre-CCI), one-way repeated measures ANOVA and Bonferroni's multiple comparison test. Data are expressed as means \pm SEM. $n=9$ male mice per genotype.

\section{Discussion}

\subsection{Alox5-KI Mice Are Leukotriene Deficient but Exhibit an Increased Capacity for} 15-HETE Formation

Previous in vitro mutagenesis studies on recombinant ALOX5 orthologs of different vertebrates (humans, mice, zebrafish) indicated that combined mutations of the triad determinants induced a switch in reaction specificity from AA 5-lipoxygenation to AA 15-lipoxygenation $[32,33,56]$. To test whether a similar mutagenesis will also modify the reaction specificity of the mouse Alox 5 ortholog in vivo, we created Alox5-KI mice, which express the Alox5 Phe359Trp + Ala424Ile + Asn425Met triple mutant instead of the wildtype enzyme [34]. Since the Alox5 gene is predominantly expressed in white blood cells, we first performed ex vivo Alox5 activity assays using heparinized peripheral blood. For this purpose, we incubated total blood with calcium ionophore A23187 and quantified relevant eicosanoids $\left(\mathrm{LTB}_{4}\right.$, 5-HETE, 15-HETE, 12-HETE, 9-HETE, 20-HETE) formed from endogenously released arachidonic acid. Our data indicate (Figure 2) that the Alox5-KI mice are leukotriene deficient but that the 15-HETE plasma levels are not significantly elevated in Alox5-KI mice. To obtain additional evidence for the leukotriene deficiency of our Alox5-KI mice we compared the pattern of selected reaction products formed from exogenously added and endogenously released AA by peritoneal lavage and bone marrow cells. Although both cell preparations are not homogenous but consist of different cell types, they are a reliable source for the catalytically active Alox 5 protein and preparation of these cells is rather simple. When we characterized the major oxygenation products formed from exogenously added AA by these cell preparations, we observed attenuated formation of $5 S$ HETE but augmented formation of 15S-HETE (Figure 3). Similarly, when the AA cascade was initiated by the release of endogenous AA (stimulation of the cells with calcium ionophore) we found that the formation of 5-HETE and $\mathrm{LTB}_{4}$ was almost completely abolished. In contrast, endogenous 15-HETE formation was augmented (Figure 4). When similar activity assays were carried out in the presence of $10 \mu \mathrm{M}$ zileuton formation of 5-HETE and $\mathrm{LTB}_{4}$ by wildtype cells was also completely abolished and 15-HETE formation by Alox5-KI cells was reduced to wildtype levels (Figures S1 and S2). Taken together, these data indicate that our genetic manipulations converted the wildtype Alox5 to an enzyme species that preferentially catalyzes AA 15-lipoxygenation. However, the sensitivity of the enzyme for the specific ALOX5 inhibitor zileuton was not altered.

\subsection{Alox5-KI Mice and Alox5 ${ }^{-1-}$ Animals Exhibit Differential Effects on EAE Score Kinetics}

Leukotrienes, the major products of the ALOX5 pathway, are pro-inflammatory mediators [1] and thus interruption of their biosynthesis by systemic inactivation of the Alox5 gene should induce anti-inflammatory effects. In fact, systemic Alox 5 deficiency reduced 
the degree of inflammatory symptoms in some but not in all peripheral inflammation models [16]. In neuro-inflammation, the biological roles of leukotrienes are less well documented. Antagonism at the leukotriene B4 receptor [57], dual ALOX5-COX inhibition [58] and prevention of leukotriene biosynthesis [40] attenuated EAE development, and these data are consistent with the assumption that systemic Alox 5 deficiency should protect mice form the development of EAE symptoms. In contrast, $A l o x 5^{-/-}$mice, which are unable to synthesize leukotrienes, developed more intense symptoms in the EAE model [35]. The mechanistic basis for this unexpected observation remains unclear but it might well be that in the central nervous system leukotrienes may mediate neuroprotective functions. When we tested our Alox5-KI mice, which also exhibit defective leukotriene biosynthesis, in the EAE model we also observed a trend to more intense neurological symptoms. Except for the cumulative incidence rate (Figure 5A), the observed differences did not reach the level of statistical significance (Figure 5B). To explain this outcome, one should keep in mind that our knock-in strategy did not only abolish the endogenous leukotriene biosynthesis [34] but it also upregulated the formation of 13-HODE [34] and 15-HETE (Figures 3 and 4). These compounds function as co-activators of PPARgamma [59,60]. Since PPARgamma activation has anti-inflammatory effects, improvement of the clinical outcome was expected. In other words, the first consequence of our knock-in strategy (prevention of endogenous leukotriene biosynthesis), which leads to exacerbation of the EAE symptoms, is counteracted by the second consequence (augmented biosynthesis of 13-HODE and 15-HETE), which should reduce inflammatory symptoms. This mechanistic scenario is consistent with our experimental observation (Figure 5B), but still does not explain why Alox $5^{-/-}$mice are more sensitive than wildtype controls in the EAE model [35].

\subsection{Alox5-KI Mice in the DSS Colitis Model}

Because of its key role in the biosynthesis of inflammatory leukotrienes, ALOX5 is considered a pro-inflammatory enzyme [16]. Experiments with the specific ALOX5 inhibitor (zileuton) in different murine colitis models have indicated that interference with endogenous leukotriene biosynthesis protected the animals from colitis development $[36,45]$. Treatment of rats with zileuton also improved the outcome of intestinal inflammation, and the degree of the protective effect was comparable with that induced by systemic application of the frequently used specific COX2 inhibitor celecoxib [61]. Since our Alox5-KI mice were unable to biosynthesize leukotrienes [34], it was expected that these animals should also be protected from DSS-induced colitis. However, our data (Figures 6C,D and S4) indicate that male mice were not protected in the DSS colitis model. For most clinical readout parameters of colitis severity (body weight kinetics, colon shortening, DAI), we did not observe significant differences between Alox5-KI mice and wildtype controls. For females, we did not observe significant differences in the body weight kinetics (Figure 6A), but did detect subtle but significant differences in the degree of colon shortening (Figure 6B) and the DAI (Figure S4). However, these differences are clearly less pronounced than those observed in the pharmacological intervention studies using the ALOX5 inhibitor zileuton $[36,45,61]$. For the time being, the molecular basis for the observation that our Alox5-KI mice behave differently than Alox $5^{-/-}$mice has not been explored. It should, however, be stressed that our genetic manipulation not only induced dysfunctional leukotriene biosynthesis [34] but also upregulated the formation of the ALOX15 products 15-HETE (Figure 3A vs. Figure 3B, Figure 4E vs. Figure 4F) and 13-HODE [34]. In DSS colitis, systemic inactivation of the Alox15 gene (Alox15 $5^{-/-}$mice) protected female mice from the development of colitis symptoms and transgenic expression of human ALOX15 under the control of the aP2 promoter deteriorated the outcome of the disease [28]. In other words, in DSS colitis the first effect of our genetic manipulation (prevention of endogenous leukotriene biosynthesis) is likely to induce less severe colitis symptoms but this protective effect might be compensated by the augmented formation of Alox 15 products by the mutant enzyme. 


\subsection{Alox5 and Neuropathic Pain}

Previous experiments suggested that ALOX inhibitors exhibited analgesic effects in different animal pain models, such as somatic inflammatory pain $[49,50]$ as well as back and neuropathic pain $[36,51]$. Here we explored whether genetically modified mice (Alox5-KI mice) expressing an Alox 5 variant that is not capable of synthesizing pro-inflammatory leukotrienes [34] are protected from pain development in the CCI model. Interestingly, we found that these mice (Figure 7) were not protected, and this data suggests that the formation of leukotrienes may not play a major patho-physiological role in the CCI pain model. Unfortunately, to the best of our knowledge Alox $5^{-/-}$mice have not been tested in this particular pain model, and thus the two genotypes (Alox5 knock-out vs. Alox5 knock-in) cannot directly be compared.

\section{Materials and Methods}

\subsection{Chemicals}

The chemicals used for the characterization experiments were obtained from the following sources: 5,8,11,14-all-cis-eicosatetraenoic acid (arachidonic acid, AA), HPLC standards of 5S/R-HETE, 12S/R-HETE, 15S/R-HETE, 5S-HETE, 12S-HETE, 15S-HETE from Cayman Chem (distributed by Biomol, Hamburg, Germany); HPLC solvents from Fisher Scientific (Schwerte, Germany). The sources of the chemicals used in the animal disease models are specified in the description of the model systems.

\subsection{Genetically Modified Animals and Genotyping}

All mice were bred and maintained in a specific pathogen-free (SPF) animal facility, on $12 \mathrm{~h}: 12 \mathrm{~h}$ LD cycle according to the FELASA recommendation with food and water ad libitum. These experiments were approved by the State animal care committee (Landesamt für Gesundheit und Soziales, Berlin, Germany) and were performed according to the Guidelines for the Care and Use of Laboratory Animals adopted by the U.S. National Institutes of Health, and the ARRIVE guidelines. The following permission numbers were given: DSS colitis model (G0250/15), EAE encephalomyelitis model (G0053/12, G0085/16), CCI neuropathic pain model (G 0017/15).

All animals included in this study were independently genotyped for the Alox5 [34] gene locus. Alox5 knock-in mice (Alox5-KI), which express the Alox5 triple mutant (Phe359Trp + Ala424Ile + Asn425Met) instead of the wildtype enzyme, were created by homologous recombination of the mutant gene construct into the genome of mouse embryonic stem cells. These mice were viable, breed normally and did not show major phenotypic defects. The mice were also backcrossed into C57BL/ 6 background and C57BL/ 6 wildtype mice were used as corresponding controls.

\subsection{Cell Preparation for Functional Characterization}

To isolate bone marrow cells, the skin was removed from the hind limbs of sacrificed mice and femurs were carefully cleaned from adherent soft tissue. The acetabulum was dislocated from the hip joint and the femur was separated from the tibia at the knee joint. Both ends of each femur were cut off using a scalpel and the bone marrow cells were prepared by rinsing the bone marrow cavity of the femur with $1 \mathrm{~mL}$ PBS. Cells were washed once with $1 \mathrm{~mL}$ of PBS, pelleted by centrifugation $(800 \times g)$ and reconstituted in $0.5 \mathrm{~mL}$ of PBS. Aliquots of this suspension were used for cellular ALOX activity assays and for RNA preparation. To prepare peritoneal lavage cells, the skin was removed from the belly region of sacrificed mice and $10 \mathrm{~mL}$ of PBS were injected into the peritoneal cavity. Care was taken not to injure organs in the peritoneal cavity. After a 5 min massage period the majority of the peritoneal fluid was removed by aspiration. Subsequently, the peritoneal cavity was opened, and remaining fluid was aspirated. Cells were spun down, washed twice with PBS and reconstituted in $0.5 \mathrm{~mL}$ PBS. Aliquots of this suspension were used for ex vivo Alox activity assays. 


\subsection{RNA Extraction and qRT-PCR of the Different Alox-Isoforms}

Peritoneal macrophages or bone marrow cells prepared from each individual were disrupted in Lysing matrix D tubes containing $600 \mu \mathrm{L}$ LBP (NucleoSpin kit) with a FastPrep 24 homogenizer (MP Biomedicals $\mathrm{GmbH}$, Eschwege, Germany; $3 \times 40$ s). Debris was spun down, the supernatant was recovered and cleared using Qia-shredder columns (Qiagen $\mathrm{GmbH}$, Hilden, Germany). Total RNA was prepared from the eluate using the NucleoSpin RNA plus extraction kit (Macherey-Nagel, Düren, Germany) according to the manufacturer's instructions. The corresponding CDNA was synthesized by reverse transcription of 0.2-0.5 $\mu \mathrm{g}$ of total RNA using Tetro Reverse Transcriptase (Bioline, Luckenwalde, Germany, distributed by BioCat GmbH Heidelberg) and Oligo-dT18 primers. External amplification standards for each gene were cloned into the TOPO 2.1 vector (Invitrogen-Thermo Fisher Scientific, Dreieich, Germany) and the linearized vector with known ssDNA copy number $/ \mu \mathrm{L}$ was used as calibration standard for the PCR products. With these calibration curves, we quantified the number of mRNA copies of target genes in the total RNA extract. qRT-PCR (SensiFastSybr no-Rox Kit; Bioline, distributed by BioCat GmbH Heidelberg) was performed on a Rotor-Gene RG 3000 (Corbett Research Ltd., Saffron Walden, UK) started with a denaturation step $\left(10 \mathrm{~min}\right.$ at $\left.95^{\circ} \mathrm{C}\right)$. Afterwards, 40 cycles of amplification, each consisting of a denaturation $\left(15 \mathrm{~s}\right.$ at $\left.95^{\circ} \mathrm{C}\right)$, an annealing $\left(30 \mathrm{~s}\right.$ at $\left.65^{\circ} \mathrm{C}\right)$, and a synthesis period $\left(20 \mathrm{~s}\right.$ at $72{ }^{\circ} \mathrm{C}$ ) were carried out. A housekeeping gene $m G a p d h$ was used. The gene specific amplification primers listed in Table 2 were used (BioTez Berlin-Buch GmbH, Germany).

Table 2. Sequence of the gene specific amplification primers used for qRT-PCR.

\begin{tabular}{|c|c|c|}
\hline Gene & Forward Primer $5^{\prime} \rightarrow 3^{\prime}$ & Reverse Primer $5^{\prime} \rightarrow 3^{\prime}$ \\
\hline$m G a p d h$ & CСАTСАССАТСТTCCAGAGCGA & GGATGACCTTGCCCACAGCCTTG \\
\hline mAlox15 & GTACGCGGGCTCCAACAACGA & TCTCCGGGGCCCTTCACAGAA \\
\hline$m$ Alox $15 b$ & CCTCCCGCTTATGTCTTTCCGT & GCCCTTTGACTTTCAGCTCCGTA \\
\hline mAlox12 & GCGGCCATGTTCAGTTGCTTAC & CATCGTCACGTCGTCCTTGCTG \\
\hline$m$ Alox 5 & TCGAGTTCCCATGTTACCGCT & CTGTGGTCACTGGGAGCTTCG \\
\hline$m A l o x 12 b$ & GGTGATGGTTCGGGGTCTGTCT & GAGTCCAGAGCACCAAGAGCACA \\
\hline mAloxe12 & CTCCAGCCACCACGACACGG & GCAACGAGTCCACAATGTCCCT \\
\hline mAloxe3 & GGGCGGCTATTGAGAGGTTTGT & TCTGGTCCTTTGGCTCTTGGCT \\
\hline
\end{tabular}

\subsection{Cellular Ex Vivo Arachidonic Acid Oxygenase Activity Assays Using Exogenous Substrates}

To assay the cellular arachidonic acid oxygenase activity, the bone marrow cells and/or the peritoneal lavage cells prepared from a single individual were incubated in $1 \mathrm{~mL}$ of PBS for $15 \mathrm{~min}$ in the presence of $80 \mu \mathrm{M}$ arachidonic acid (AA). To optimize the Alox5 activity we added $100 \mu \mathrm{M}$ ATP, $100 \mu \mathrm{M}$ EDTA, $0.4 \mathrm{mM} \mathrm{Ca}^{2+}$ and $1.4 \mu \mathrm{g} / \mathrm{mL}$ soybean phosphatidylcholine to the activity assay mixture. After a $15 \mathrm{~min}$ incubation period, the hydroperoxy fatty acids formed were reduced by the addition of $1 \mathrm{mg}$ solid sodium borohydride, the samples were acidified and extracted twice with $1 \mathrm{~mL}$ of ethyl acetate. The extracts were combined, the solvent was evaporated, the extracted lipids were reconstituted in $0.5 \mathrm{~mL}$ of HPLC column solvent (acetonitrile/water/acetic acid $=70 / 30 / 0.1$, by vol) and analyzed by RP-HPLC on a Shimadzu LC-20 instrument equipped with a SIL-20AC autoinjector, a SPD-M20A diode array detector and a CTO-20AC column oven. The oxygenated fatty acids were analyzed on a Nucleodur $100-5 C_{18 \text { ec }}$ column, which was connected with a corresponding $1 \mathrm{~cm}$ guard column. Isocratic elution at $25^{\circ} \mathrm{C}$ was carried out. Metabolites were identified by the retention times and their UV-spectral properties.

Since RP-HPLC does not separate HETE enantiomers, we applied an alternative methodological approach to obtain information on the enantiomer composition of the ALOX products formed. For this purpose, the conjugated dienes formed were prepared by RP-HPLC (see legend to Figure 1) and further analyzed by a combination of normal phase and chiral phase HPLC (NP/CP-HPLC). NP-HPLC guard column Nucleosil (Nucleosil $50-5,4.6 \mathrm{~mm} \times 35 \mathrm{~mm}, 5 \mu \mathrm{m}$ particle size, Macherey-Nagel, Düren, Germany) was set in front of a CP-HPLC column (Chiralpak AD-H, $4.6 \mathrm{~mm} \times 250 \mathrm{~mm}, 5 \mu \mathrm{m}$ particle size, 
Daicel, Osaka, Japan) and the RP-HPLC purified analytes were isocratically eluted with the solvent system $\mathrm{n}$-hexane/methanol/ethanol/acetic acid (96:3:1:0.1, by vol) at a flow rate of $1 \mathrm{~mL} / \mathrm{min}$ at room temperature.

\subsection{Ex Vivo Alox5 Activity Assays Using Heparinized Whole Peripheral Blood}

For ex vivo Alox 5 activity assays, heparinized blood was collected from Alox5-KI mice and outbred WT controls. In total, $0.5 \mathrm{~mL}$ of blood was incubated for $30 \mathrm{~min}$ at $37^{\circ} \mathrm{C}$ in the presence of $50 \mu \mathrm{M}$ calcium ionophore (A23187). Blood cells were spun down, the plasma was recovered and was analyzed for relevant eicosanoids (LTB4, 5-HETE, 12-HETE, 15-HETE, 9-HETE, 20-HETE) by LC-MS/MS. In detail, $50 \mu \mathrm{L}$ plasma was spiked with external deuterated standards (14,15-EET-d8, 14,15-DHET-D11, 15-HETE-d8, 20-HETEd6, LTB4-d4, PGE2-d2, 0.1 ng each, Cayman Chem., distributed by Biomol, Hamburg, Germany). Then $450 \mu \mathrm{L}$ water, $20 \mu \mathrm{L}$ glycerol, $500 \mu \mathrm{L}$ acetonitrile and $5 \mu \mathrm{L}$ 2,6-Di-tertbutyl-4-methylphenol (BHT $10 \mathrm{mg} / \mathrm{mL}$ ) were added to the blood plasma. Then the $\mathrm{pH}$ was adjusted to 6 by addition of $2 \mathrm{~mL}$ phosphate buffer $(0.1 \mathrm{~mol} / \mathrm{L})$. Protein precipitate was removed by centrifugation and the obtained supernatant was loaded onto Bond Elute Certify II columns (Agilent Technologies) for solid-phase lipid extraction. For this purpose, the columns were preconditioned by eluting them sequentially with $3 \mathrm{~mL}$ methanol and then with $3 \mathrm{~mL}$ of $0.1 \mathrm{~mol} / \mathrm{L}$ phosphate buffer $(\mathrm{pH} \mathrm{6)}$ containing 5\% methanol. After sample application the columns were washed with $3 \mathrm{~mL}$ methanol/water $(40 / 50$, by vol) and the metabolites were eluted with $2 \mathrm{~mL}$ of a mixture of n-hexane: ethyl acetate (25: 75 containing $1 \%$ acetic acid). The solvents were evaporated on a heating block at $40{ }^{\circ} \mathrm{C}$ under a stream of nitrogen and the remaining lipids were reconstituted in $100 \mu \mathrm{L}$ of a methanol/water mixture (60:40, by vol).

The samples were analyzed using an Agilent 1290 HPLC system (Agilent, Waldbronn, Germany) with binary pump, multisampler and column thermostat using an Agilent Zorbax Eclipse plus C- 18 column $(2.1 \times 150 \mathrm{~mm}, 1.8 \mu \mathrm{m}$ particle size $)$ with a solvent system consisting of aqueous acetic acid $(0.05 \%)$ and acetonitrile. The elution gradient was started with $5 \%$ acetonitrile, which was increased within $0.5 \mathrm{~min}$ to $32 \%, 16 \mathrm{~min}$ to $36.5 \%, 20 \mathrm{~min}$ to $38 \%, 28 \mathrm{~min}$ to $98 \%$ and held there for $5 \mathrm{~min}$. The flow rate was set at $0.3 \mathrm{~mL} / \mathrm{min}$, the injection volume was $20 \mu \mathrm{L}$. The HPLC was coupled with an Agilent 6495 Triplequad mass spectrometer (Agilent, Waldbronn, Germany) with electrospray ionisation source and the following source parameters were employed: drying gas $\left(115^{\circ} \mathrm{C} / 16 \mathrm{~L} / \mathrm{min}\right)$, sheath gas $\left(390^{\circ} \mathrm{C} / 12 \mathrm{~L} / \mathrm{min}\right)$, capillary voltage $(4300 \mathrm{~V})$, nozzel voltage $(1950 \mathrm{~V})$ and Nebulizer pressure ( $35 \mathrm{psi}$ ). Analysis was carried out using Multiple Reaction Monitoring in negative mode. The GraphPad Prism software version 8.0.0 for iOS was used to structure Figure 2 (GraphPad Software, San Diego, CA, USA, www.graphpad.com, accessed on 26 July 2021).

\subsection{Ex Vivo Formation of LTB4, 5-HETE and 15-HETE by Isolated Bone Marrow Cells Using Endogenous $A A$ as Substrate}

To explore whether the mutagenesis induced alterations in the cellular eicosanoid metabolism (abolished 5-HETE and $\mathrm{LTB}_{4}$ formation and increased formation of 15-HETE) can be confirmed when endogenous substrates were used, we isolated bone marrow cells from female Alox5-KI mice and corresponding WT controls. Cells were washed and then reconstituted in PBS reaching a final cell concentration of $4 \times 10^{-7}$ per mL. In total, $0.5 \mathrm{~mL}$ of these cellular stock solutions $\left(2 \times 10^{-7}\right.$ cells) were taken and used for the activity assays. The ALOX reaction was initiated by the addition of $5 \mu \mathrm{M}$ calcium ionophore A23187 and the cells were incubated for $5 \mathrm{~min}$ at room temperature. After the incubation period the sample was acidified by the addition of glacial acetic acid and the total lipids were extracted twice with $1 \mathrm{~mL}$ of ethyl acetate. The extracts were pooled, the solvent was evaporated, and the remaining lipids were reconstituted in $0.05 \mathrm{~mL}$ of methanol and analyzed for the formation of 5-HETE, 15-HETE and $\mathrm{LTB}_{4}$ by LC-MS/MS. For some experiments the cells were pretreated with the specific ALOX5 inhibitor zileuton before the Alox reaction was initiated. In these cases, cells $\left(0.5 \mathrm{~mL}\right.$ involving $2 \times 10^{-7}$ cells $)$ were pre-incubated in the presence of $10 \mu \mathrm{M}$ zileuton at $37^{\circ} \mathrm{C}$ for $20 \mathrm{~min}$. After pre-incubation, cells were spun down, 
washed once with PBS and reconstituted in $0.5 \mathrm{~mL}$ of PBS. Then the Alox reaction with endogenous substrate was initiated by addition of calcium ionophore.

For LC-MS/MS analysis the lipid extracts were spiked with deuterated internal standards including ${ }^{2} \mathrm{H}_{4}$-LTB $4,{ }^{2} \mathrm{H}_{4}-9$-HODE, ${ }^{2} \mathrm{H}_{8}$-5-HETE, ${ }^{2} \mathrm{H}_{8}$-12-HETE and ${ }^{2} \mathrm{H}_{6}$-20-HETE, and quantification of the Alox products was carried out by LC-MS/MS [37]. In brief, chromatographic separation of the reaction products (injection volume $5-10 \mu \mathrm{L}$ ) was carried out on an Agilent LC instrument (Agilent, Waldbronn, Germany) equipped with an Agilent Zorbax Eclipse Plus C18 reversed phase column $(2.1 \times 150 \mathrm{~mm}$, particle size $1.8 \mu \mathrm{m})$. A binary solvent gradient with $0.1 \%$ aqueous acetic acid as solvent $\mathrm{A}$ and acetonitrile/methanol/acetic acid $(800 / 150 / 1, v / v / v)$ as solvent $B$ at a flow rate of $0.3 \mathrm{~mL} / \mathrm{min}$ was used. Mass spectrometric detection was performed on an AB Sciex 6500 QTRAP instrument (SCIEX, Darmstadt, Germany) in the selected reaction monitoring mode following negative electrospray ionization. Data analysis was carried out with Multiquant 2.1.1. software package.

\subsection{Experimental Autoimmune Encephalomyelitis (EAE) Model}

To induce active EAE, 12-week-old female wildtype and Alox5-KI mice were immunized subcutaneously with $200 \mu \mathrm{L}$ of myelin oligodendrocyte glycoprotein peptide 35-55 (MOG35-55) (Pepceuticals, Leicester, UK) emulsified in complete Freund's adjuvant (Difco Laboratories, Detroit, MI, USA) containing $800 \mu \mathrm{g}$ Mycobacterium tuberculosis H37Ra (Difco). At the day of immunization and $48 \mathrm{~h}$ later, mice were intraperitoneally injected with Pertussis toxin ( $200 \mathrm{ng}$, Sigma-Aldrich, St. Louis, MO, USA). Clinical symptoms were monitored daily and scored as follows: 0 , no symptoms; 0.5 , tail weakness; 1 , lack of tail tone; 1.5 , no righting reflex; 2 , hind-limb weakness; 2.5 , partial hind-limb paralysis; 3 , total hind-limb paralysis; 3.5 , ascending fore-limb paralysis. Statistical analyses of the experimental raw data obtained were performed using the SPSS software packages. Cumulative incidences were statistically analyzed by the Log-Rank test (Figure 4A). Time-course data (Figure 4B) between two genotypes were compared by mixed analysis of variance (ANOVA) using the Greenhouse-Geisser correction. The normalized spleen weight data (Figure 4C) for the two genotypes were evaluated with the Mann-Whitney U-test. Differences were considered significant at values of $p<0.05$.

\subsection{Dextran Sodium Sulfate (DSS)-Induced Colitis Model}

For induction of colitis, 12-week-old wildtype (5 males and 5 females) and Alox5KI ( 5 males and 5 females) mice received $2.5 \%$ (wt/vol) dextran sodium sulfate (DSS; molecular weight $=36,000-50,000$; MP Biomedicals, Eschwege, Germany) in the drinking water for 6 days followed by 3 days of normal drinking water. On the 9 th day mice were sacrificed by isoflurane anesthesia and cervical dislocation. The colon was prepared, colon length was determined, and colonic tissue was snap frozen.

Statistical analyses of the experimental raw data obtained in this series of experiments were performed using the SPSS Statistics software packages. Comparison of two groups were performed using Mann-Whitney $\mathrm{U}$ test. The time-course data of the two genotypes were compared by mixed analysis of variance (ANOVA, using Greenhouse-Geisser correction). Differences were considered significant at values of $p<0.05$.

\subsection{Chronic Constriction Injury (CCI) Model of Neuropathic Pain}

Alox5-KI mice and corresponding wildtype controls (26-32 g, 10-11 weeks old; bred at the Charité-Campus Benjamin Franklin, Berlin, Germany) were kept in groups of 3 per cage, with free access to food and water, in environmentally controlled conditions ( $12 \mathrm{~h}$ light/dark schedule, light on at 7:00 $\mathrm{h} ; 22-24{ }^{\circ} \mathrm{C}$; humidity $60-65 \%$ ). The experiments were performed by an experimenter blinded to the genotypes. The codes were broken after completion of the experiments. After the experiments the animals were killed with an overdose of isoflurane. 
CCI was induced in deeply isoflurane-anesthetized mice. The sciatic nerve was exposed at the level of the right mid-thigh and three loose silk ligatures (4/0) were placed around the nerve with $1 \mathrm{~mm}$ spacing. The ligatures were tied until they elicited a brief twitch in the right hind limb. The wound was closed with silk sutures [54,55,62].

Mechanical sensitivity was assessed using the von Frey test. For this purpose, the animals were habituated to the test cages daily (1-2 times for $15 \mathrm{~min}$ ), starting 6 days prior to nociceptive testing; they were individually placed in clear Plexiglas chambers located on a stand with anodized mesh (Model 410; IITC Life Sciences, Woodland Hills, Los Angeles, CA, USA). To assess the sensitivity, calibrated von Frey filaments in the range of $0.054 \mathrm{mN}$ $(0.0056 \mathrm{~g})$ to $42.85 \mathrm{mN}$ (4.37 g) were used. The filaments were applied until they bowed, for approximately $3 \mathrm{~s}$, to the plantar surface of hind paws. The up-down method was used to estimate $50 \%$ withdrawal thresholds [63]. Testing was started using a $2.74 \mathrm{mN}(0.28 \mathrm{~g})$ filament. If the animal withdrew the paw, the preceding weaker filament was applied. In the absence of withdrawal, the next stronger filament was applied. The maximum number of applications was 6-9, and the cut-off was $42.85 \mathrm{mN}$ (4.37 g) according to our previous studies $[54,55,62]$.

Heat sensitivity was assessed using the Hargreaves test. Mice were habituated to the test cages daily (1-2 times for $15 \mathrm{~min}$ ), starting 6 days prior to nociceptive testing; they were placed in clear Plexiglas chambers positioned on a stand with a glass surface (Model 336; IITC Life Sciences, Woodland Hills, Los Angeles, CA, USA). To examine heat sensitivity, radiant heat was applied to the plantar surface of hind paws from underneath the glass floor with a high intensity projector lamp bulb and paw withdrawal latency was evaluated using an electronic timer. The withdrawal latency was defined as the average of two measurements separated by at least $10 \mathrm{~s}$. The heat intensity was adjusted to obtain baseline withdrawal latency of about 10-12 s in uninjured paws, and the cut-off was set at $20 \mathrm{~s}$ to avoid tissue damage $[55,62,64]$. Mechanical and heat sensitivity were evaluated in the same groups of mice with an interval of at least one hour between the tests, a day before and then daily on days 1-21 after CCI. Nine wildtype and nine Alox5-KI male mice were used. Statistical analyses of the experimental raw data obtained in this series of experiments were performed using GraphPad Prism software (Version 5.02 for Windows; GraphPad Software Inc.). Two groups over time were compared by two-way repeated measures analysis of variance (ANOVA). Multiple comparisons over time within one group were performed by one-way repeated measures ANOVA followed by Bonferroni's multiple comparison test. Differences were considered significant at values of $p<0.05$.

\section{Conclusions}

As Alox 5 knock-out mice (Alox $5^{-/-}$), our Alox5 knock-in mice (Alox5-KI mice) expressing an arachidonic acid 15-lipoxygenating Alox 5 mutant were leukotriene deficient. However, in the EAE disease model the two genotypes exhibited differential effects, which might be related to the increased capability of the mutant Alox5 to synthesize 15-H(p)ETE and/or 15-H(p)ETE derived secondary products. In two other animal inflammation models (DSS colitis model, CCI model of neuropathic pain) the Alox5-KI mice behaved like wildtype control animals.

Supplementary Materials: The following items are available online at https:/ / www.mdpi.com/ article/10.3390/metabo11100698/s1: Figure S1: Impact of the ALOX5 specific inhibitor zileuton on 5-HETE formation of bone marrow cells from endogenous arachidonic acid, Figure S2: Impact of the ALOX5 specific inhibitor zileuton on 15-HETE formation of bone marrow cells from endogenous arachidonic acid, Figure S3: Comparison of different lymphocyte populations in the peripheral blood of Alox5-KI mice and corresponding wildtype control animals at the end (day 22) of the experimental protocol of the EAE model, Figure S4: Disease activity index of male and female mice at the end (day 9) of the DSS-induced experimental colitis. 
Author Contributions: The study was designed by E.M.-B. and H.K. The characterization experiments of the genetically modified mice were carried out by H.K. and E.M.-B. M.R. performed the LC-MS/MS analyses of the blood plasma levels of different plasma eicosanoids. The EAE experiments were performed by S.R.-S. under the supervision of C.I.-D. The DSS colitis experiments were carried out by N.R. under the supervision of K.H.W. The CCI experiments were performed by D.L. under the supervision of H.M. L.K. carried out the LC-MS/MS analyses of 15-HETE, 5-HETE and $\mathrm{LTB}_{4}$ that were formed during ex vivo activity assays using endogenous substrates under supervision of N.H.S. D.H. performed RNA extraction and qRT-PCR of the different Alox mRNAs. E.M.-B. and H.K. coordinated the work and H.K. drafted the manuscript. H.K., P.R. and L.H.W. contributed to fund raising. All co-authors contributed to manuscript writing. All authors have read and agreed to the published version of the manuscript.

Funding: This research was funded by research grants of Deutsche Forschungsgemeinschaft to H.K. (Ku 961/11-1, Ku961/13-1) and NS (Sche1801).

Institutional Review Board Statement: The study was conducted according to the guidelines of the Declaration of Helsinki and approved by the Institutional Review Board of the State Animal Care Committee (Landesamt für Gesundheit und Soziales, Berlin, Germany) and the following permission numbers were given: DSS colitis model (G0250/15), EAE encephalomyelitis model (G0053/12, G0085/16), CCI neuropathic pain model (G 0017/15). version.

Informed Consent Statement: Not applicable.

Data Availability Statement: The data presented in this paper is available on request from the corresponding author. The original experimental raw data are not publicly available. They are kept by the researchers who carried out the different experiments (see Authors Contribution) but will be send on request to interested scientists.

Conflicts of Interest: The authors declare no conflict of interest. The funders had no role in the design of the study; in the collection, analyses, or interpretation of data; in the writing of the manuscript, or in the decision to publish the results.

\section{References}

1. Haeggstrom, J.Z.; Funk, C.D. Lipoxygenase and leukotriene pathways: Biochemistry, biology, and roles in disease. Chem. Rev. 2011, 111, 5866-5898. [CrossRef]

2. Kuhn, H.; Banthiya, S.; van Leyen, K. Mammalian lipoxygenases and their biological relevance. Biochim. Biophys. Acta 2015, 1851, 308-330. [CrossRef] [PubMed]

3. Liu, M.; Yokomizo, T. The role of leukotrienes in allergic diseases. Allergol. Int. 2015, 64, 17-26. [CrossRef] [PubMed]

4. Serhan, C.N.; Chiang, N. Resolution phase lipid mediators of inflammation: Agonists of resolution. Curr. Opin. Pharmacol. 2013, 13, 632-640. [CrossRef]

5. Kuhn, H.; Humeniuk, L.; Kozlov, N.; Roigas, S.; Adel, S.; Heydeck, D. The evolutionary hypothesis of reaction specificity of mammalian ALOX15 orthologs. Prog. Lipid Res. 2018, 72, 55-74. [CrossRef]

6. Borgeat, P.; Hamberg, M.; Samuelsson, B. Transformation of arachidonic acid and homo-gamma-linolenic acid by rabbit polymorphonuclear leukocytes. Monohydroxy acids from novel lipoxygenases. J. Biol. Chem. 1976, 251, 7816-7820. [CrossRef]

7. Morgan, E.L.; Maskrey, B.H.; Rowley, A.F. At what stage in metazoan evolution did leukotriene generation first appear?-key insights from cartilaginous fish. Dev. Comp. Immunol. 2005, 29, 53-59. [CrossRef] [PubMed]

8. Yuan, D.; Zou, Q.; Yu, T.; Song, C.; Huang, S.; Chen, S.; Ren, Z.; Xu, A. Ancestral genetic complexity of arachidonic acid metabolism in Metazoa. Biochim. Biophys. Acta 2014, 1841, 1272-1284. [CrossRef] [PubMed]

9. Tholander, F.; Muroya, A.; Roques, B.P.; Fournié-Zaluski, M.C.; Thunnissen, M.M.; Haeggström, J.Z. Structure-based dissection of the active site chemistry of leukotriene A4 hydrolase: Implications for M1 aminopeptidases and inhibitor design. Chem. Biol. 2008, 15, 920-929. [CrossRef]

10. Martinez Molina, D.; Wetterholm, A.; Kohl, A.; McCarthy, A.A.; Niegowski, D.; Ohlson, E.; Hammarberg, T.; Eshaghi, S.; Haeggström, J.Z.; Nordlund, P. Structural basis for synthesis of inflammatory mediators by human leukotriene C4 synthase. Nature 2007, 448, 613-616. [CrossRef] [PubMed]

11. Ohnishi, H.; Miyahara, N.; Gelfand, E.W. The role of leukotriene B(4) in allergic diseases. Allergol. Int. 2008, 57, 291-298. [CrossRef] [PubMed]

12. Smith, M.J. Biological activities of leukotriene B4. Agents Actions 1981, 11, 571-572. [CrossRef] [PubMed]

13. Marom, Z.; Shelhamer, J.H.; Bach, M.K.; Morton, D.R.; Kaliner, M. Slow-reacting substances, leukotrienes C4 and D4, increase the release of mucus from human airways in vitro. Am. Rev. Respir. Dis. 1982, 126, 449-451. [PubMed]

14. Matsuse, H.; Kohno, S. Leukotriene receptor antagonists pranlukast and montelukast for treating asthma. Expert Opin. Pharmacother. 2014, 15, 353-363. [CrossRef] 
15. Berger, W.; De Chandt, M.T.; Cairns, C.B. Zileuton: Clinical implications of 5-Lipoxygenase inhibition in severe airway disease. Int. J. Clin. Pract. 2007, 61, 663-676. [CrossRef] [PubMed]

16. Chen, X.S.; Sheller, J.R.; Johnson, E.N.; Funk, C.D. Role of leukotrienes revealed by targeted disruption of the 5-lipoxygenase gene. Nature 1994, 372, 179-182. [CrossRef] [PubMed]

17. Zhao, L.; Moos, M.P.; Grabner, R.; Pedrono, F.; Fan, J.; Kaiser, B.; John, N.; Schmidt, S.; Spanbroek, R.; Lotzer, K.; et al. The 5-lipoxygenase pathway promotes pathogenesis of hyperlipidemia-dependent aortic aneurysm. Nat. Med. 2004, 10, 966-973. [CrossRef]

18. Schewe, T.; Halangk, W.; Hiebsch, C.; Rapoport, S.M. A lipoxygenase in rabbit reticulocytes which attacks phospholipids and intact mitochondria. FEBS Lett. 1975, 60, 149-152. [CrossRef]

19. Rapoport, S.M.; Schewe, T.; Wiesner, R.; Halangk, W.; Ludwig, P.; Janicke-Hohne, M.; Tannert, C.; Hiebsch, C.; Klatt, D. The lipoxygenase of reticulocytes. Purification, characterization and biological dynamics of the lipoxygenase; its identity with the respiratory inhibitors of the reticulocyte. Eur. J. Biochem. 1979, 96, 545-561. [CrossRef]

20. Vogel, R.; Jansen, C.; Roffeis, J.; Reddanna, P.; Forsell, P.; Claesson, H.E.; Kuhn, H.; Walther, M. Applicability of the triad concept for the positional specificity of mammalian lipoxygenases. J. Biol. Chem. 2010, 285, 5369-5376. [CrossRef]

21. Adel, S.; Karst, F.; Gonzalez-Lafont, A.; Pekarova, M.; Saura, P.; Masgrau, L.; Lluch, J.M.; Stehling, S.; Horn, T.; Kuhn, H.; et al. Evolutionary alteration of ALOX15 specificity optimizes the biosynthesis of antiinflammatory and proresolving lipoxins. Proc. Natl. Acad. Sci. USA 2016, 113, E4266-E4275. [CrossRef] [PubMed]

22. Kozlov, N.; Humeniuk, L.; Ufer, C.; Ivanov, I.; Golovanov, A.; Stehling, S.; Heydeck, D.; Kuhn, H. Functional characterization of novel ALOX15 orthologs representing key steps in mammalian evolution supports the Evolutionary Hypothesis of reaction specificity. Biochim. Biophys. Acta Mol. Cell Biol. Lipids 2018, 1864, 372-385. [CrossRef] [PubMed]

23. Bryant, R.W.; Bailey, J.M.; Schewe, T.; Rapoport, S.M. Positional specificity of a reticulocyte lipoxygenase. Conversion of arachidonic acid to 15-S-hydroperoxy-eicosatetraenoic acid. J. Biol. Chem. 1982, 257, 6050-6055. [CrossRef]

24. Kutzner, L.; Goloshchapova, K.; Heydeck, D.; Stehling, S.; Kuhn, H.; Schebb, N.H. Mammalian ALOX15 orthologs exhibit pronounced dual positional specificity with docosahexaenoic acid. Biochim. Biophys. Acta 2017, 1862, 666-675. [CrossRef] [PubMed]

25. Sun, D.; Funk, C.D. Disruption of 12/15-lipoxygenase expression in peritoneal macrophages. Enhanced utilization of the 5-lipoxygenase pathway and diminished oxidation of low density lipoprotein. J. Biol. Chem. 1996, 271, 24055-24062. [CrossRef] [PubMed]

26. Taylor, P.R.; Heydeck, D.; Jones, G.W.; Krönke, G.; Funk, C.D.; Knapper, S.; Adams, D.; Kühn, H.; O’Donnell, V.B. Development of myeloproliferative disease in 12/15-lipoxygenase deficiency. Blood 2012, 119, 6173-6174. [CrossRef]

27. Kronke, G.; Katzenbeisser, J.; Uderhardt, S.; Zaiss, M.M.; Scholtysek, C.; Schabbauer, G.; Zarbock, A.; Koenders, M.I.; Axmann, R.; Zwerina, J.; et al. 12/15-lipoxygenase counteracts inflammation and tissue damage in arthritis. J. Immunol. 2009, 183, 3383-3389. [CrossRef]

28. Kroschwald, S.; Chiu, C.Y.; Heydeck, D.; Rohwer, N.; Gehring, T.; Seifert, U.; Lux, A.; Rothe, M.; Weylandt, K.H.; Kuhn, H. Female mice carrying a defective Alox 15 gene are protected from experimental colitis via sustained maintenance of the intestinal epithelial barrier function. Biochim. Biophys. Acta Mol. Cell Biol. Lipids 2018, 1863, 866-880. [CrossRef]

29. Spite, M.; Claria, J.; Serhan, C.N. Resolvins, specialized proresolving lipid mediators, and their potential roles in metabolic diseases. Cell Metab. 2014, 19, 21-36. [CrossRef]

30. Martin, H. Role of PPAR-gamma in inflammation. Prospects for therapeutic intervention by food components. Mutat. Res. 2010, 690, 57-63. [CrossRef]

31. Serhan, C.N.; Petasis, N.A. Resolvins and protectins in inflammation resolution. Chem. Rev. 2011, 111, 5922-5943. [CrossRef]

32. Schwarz, K.; Walther, M.; Anton, M.; Gerth, C.; Feussner, I.; Kuhn, H. Structural basis for lipoxygenase specificity. Conversion of the human leukocyte 5-lipoxygenase to a 15-lipoxygenating enzyme species by site-directed mutagenesis. J. Biol. Chem. 2001, 276, 773-779. [CrossRef] [PubMed]

33. Hofheinz, K.; Kakularam, K.R.; Adel, S.; Anton, M.; Polymarasetty, A.; Reddanna, P.; Kuhn, H.; Horn, T. Conversion of pro-inflammatory murine Alox5 into an anti-inflammatory 15S-lipoxygenating enzyme by multiple mutations of sequence determinants. Arch. Biochem. Biophys. 2013, 530, 40-47. [CrossRef] [PubMed]

34. Marbach-Breitrück, E.; Kutzner, L.; Rothe, M.; Gurke, R.; Schreiber, Y.; Reddanna, P.; Schebb, N.-H.; Stehling, S.; Wieler, L.; Heydeck, D.; et al. Functional charcterization of knock-in mice expressing a 12/15-lipoxygenating Alox 5 mutant instead of the 5-lipoxygenating wild-type enzyme. Antioxid. Redox Signal. 2020, 32, 1-17. [CrossRef] [PubMed]

35. Emerson, M.R.; LeVine, S.M. Experimental allergic encephalomyelitis is exacerbated in mice deficient for 12/15-lipoxygenase or 5-lipoxygenase. Brain Res. 2004, 1021, 140-145. [CrossRef] [PubMed]

36. Singh, V.P.; Patil, C.S.; Kulkarni, S.K. Effect of 5-lipoxygenase inhibition on events associated with inflammatory bowel disease in rats. Indian J. Exp. Biol. 2004, 42, 667-673. [PubMed]

37. Rund, K.M.; Ostermann, A.I.; Kutzner, L.; Galano, J.M.; Oger, C.; Vigor, C.; Wecklein, S.; Seiwert, N.; Durand, T.; Schebb, N.H. Development of an LC-ESI(-)-MS/MS method for the simultaneous quantification of 35 isoprostanes and isofurans derived from the major n3- and n6-PUFAs. Anal. Chim. Acta 2018, 1037, 63-74. [CrossRef]

38. Steinhilber, D.; Hofmann, B. Recent advances in the search for novel 5-lipoxygenase inhibitors. Basic Clin. Pharmacol. Toxicol. 2014, 114, 70-77. [CrossRef] 
39. Constantinescu, C.S.; Farooqi, N.; O'Brien, K.; Gran, B. Experimental autoimmune encephalomyelitis (EAE) as a model for multiple sclerosis (MS). Br. J. Pharmacol. 2011, 164, 1079-1106. [CrossRef]

40. Wildfeuer, A.; Neu, I.S.; Safayhi, H.; Metzger, G.; Wehrmann, M.; Vogel, U.; Ammon, H.P. Effects of boswellic acids extracted from a herbal medicine on the biosynthesis of leukotrienes and the course of experimental autoimmune encephalomyelitis. Arzneim.-Forsch. 1998, 48, 668-674.

41. Xu, J.; Zhang, Y.; Xiao, Y.; Ma, S.; Liu, Q.; Dang, S.; Jin, M.; Shi, Y.; Wan, B.; Zhang, Y. Inhibition of 12/15-lipoxygenase by baicalein induces microglia PPARbeta/delta: A potential therapeutic role for CNS autoimmune disease. Cell Death Dis. 2013, 4, e569. [CrossRef] [PubMed]

42. Kong, W.; Hooper, K.M.; Ganea, D. The natural dual cyclooxygenase and 5-lipoxygenase inhibitor flavocoxid is protective in EAE through effects on Th1/Th17 differentiation and macrophage/microglia activation. Brain Behav. Immun. 2016, 53, 59-71. [CrossRef] [PubMed]

43. Whitney, L.W.; Ludwin, S.K.; McFarland, H.F.; Biddison, W.E. Microarray analysis of gene expression in multiple sclerosis and EAE identifies 5-lipoxygenase as a component of inflammatory lesions. J. Neuroimmunol. 2001, 121, 40-48. [CrossRef]

44. DeVoss, J.; Diehl, L. Murine models of inflammatory bowel disease (IBD): Challenges of modeling human disease. Toxicol. Pathol. 2014, 42, 99-110. [CrossRef]

45. Mazzon, E.; Sautebin, L.; Caputi, A.P.; Cuzzocrea, S. 5-lipoxygenase modulates the alteration of paracellular barrier function in mice ileum during experimental colitis. Shock 2006, 25, 377-383. [CrossRef]

46. Davies, P.; Bailey, P.J.; Goldenberg, M.M.; Ford-Hutchinson, A.W. The role of arachidonic acid oxygenation products in pain and inflammation. Annu. Rev. Immunol. 1984, 2, 335-357. [CrossRef]

47. Levine, J.D.; Lam, D.; Taiwo, Y.O.; Donatoni, P.; Goetzl, E.J. Hyperalgesic properties of 15-lipoxygenase products of arachidonic acid. Proc. Natl. Acad. Sci. USA 1986, 83, 5331-5334. [CrossRef]

48. Hwang, S.W.; Cho, H.; Kwak, J.; Lee, S.Y.; Kang, C.J.; Jung, J.; Cho, S.; Min, K.H.; Suh, Y.G.; Kim, D.; et al. Direct activation of capsaicin receptors by products of lipoxygenases: Endogenous capsaicin-like substances. Proc. Natl. Acad. Sci. USA 2000, 97, 6155-6160. [CrossRef]

49. Lai, H.C.; Lu, C.H.; Wong, C.S.; Lin, B.F.; Chan, S.M.; Kuo, C.Y.; Wu, Z.F. Baicalein attenuates neuropathic pain and improves sciatic nerve function recovery in rats with partial sciatic nerve transection. J. Chin. Med. Assoc. 2018, 81, 955-963. [CrossRef]

50. Aley, O.; Levine, J.D. Contribution of 5- and 12-lipoxygenase products to mechanical hyperalgesia induced by prostaglandin $\mathrm{E}(2)$ and epinephrine in the rat. Exp. Brain Res. 2003, 148, 482-487. [CrossRef]

51. Singh, V.P.; Patil, C.S.; Kulkarni, S.K. Effect of zileuton in radicular pain induced by herniated nucleus pulposus in rats. Inflammopharmacology 2004, 12, 189-195. [CrossRef] [PubMed]

52. Cui, J.G.; Holmin, S.; Mathiesen, T.; Meyerson, B.A.; Linderoth, B. Possible role of inflammatory mediators in tactile hypersensitivity in rat models of mononeuropathy. Pain 2000, 88, 239-248. [CrossRef]

53. Verge, G.M.; Milligan, E.D.; Maier, S.F.; Watkins, L.R.; Naeve, G.S.; Foster, A.C. Fractalkine (CX3CL1) and fractalkine receptor (CX3CR1) distribution in spinal cord and dorsal root ganglia under basal and neuropathic pain conditions. Eur. J. Neurosci. 2004, 20, 1150-1160. [CrossRef] [PubMed]

54. Labuz, D.; Schmidt, Y.; Schreiter, A.; Rittner, H.L.; Mousa, S.A.; Machelska, H. Immune cell-derived opioids protect against neuropathic pain in mice. J. Clin. Investig. 2009, 119, 278-286. [CrossRef]

55. Labuz, D.; Machelska, H. Stronger antinociceptive efficacy of opioids at the injured nerve trunk than at its peripheral terminals in neuropathic pain. J. Pharmacol. Exp. Ther. 2013, 346, 535-544. [CrossRef]

56. Adel, S.; Heydeck, D.; Kuhn, H.; Ufer, C. The lipoxygenase pathway in zebrafish. Expression and characterization of zebrafish ALOX5 and comparison with its human ortholog. Biochim. Biophys. Acta 2016, 1861, 1-11. [CrossRef]

57. Gladue, R.P.; Carroll, L.A.; Milici, A.J.; Scampoli, D.N.; Stukenbrok, H.A.; Pettipher, E.R.; Salter, E.D.; Contillo, L.; Showell, H.J. Inhibition of leukotriene B4-receptor interaction suppresses eosinophil infiltration and disease pathology in a murine model of experimental allergic encephalomyelitis. J. Exp. Med. 1996, 183, 1893-1898. [CrossRef]

58. Simmons, R.D.; Hugh, A.R.; Willenborg, D.O.; Cowden, W.B. Suppression of active but not passive autoimmune encephalomyelitis by dual cyclo-oxygenase and 5-lipoxygenase inhibition. Acta Neurol. Scand. 1992, 85, 197-199. [CrossRef]

59. Limor, R.; Sharon, O.; Knoll, E.; Many, A.; Weisinger, G.; Stern, N. Lipoxygenase-derived metabolites are regulators of peroxisome proliferator-activated receptor gamma-2 expression in human vascular smooth muscle cells. Am. J. Hypertens. 2008, 21, 219-223. [CrossRef]

60. Zuo, X.; Wu, Y.; Morris, J.S.; Stimmel, J.B.; Leesnitzer, L.M.; Fischer, S.M.; Lippman, S.M.; Shureiqi, I. Oxidative metabolism of linoleic acid modulates PPAR-beta/delta suppression of PPAR-gamma activity. Oncogene 2006, 25, 1225-1241. [CrossRef]

61. Pallio, G.; Bitto, A.; Pizzino, G.; Galfo, F.; Irrera, N.; Minutoli, L.; Arcoraci, V.; Squadrito, G.; Macri, A.; Squadrito, F.; et al. Use of a balanced dual cyclooxygenase-1/2 and 5-lypoxygenase inhibitor in experimental colitis. Eur. J. Pharmacol. 2016, 789, 152-162. [CrossRef] [PubMed]

62. Labuz, D.; Celik, M.Ö.; Zimmer, A.; Machelska, H. Distinct roles of exogenous opioid agonists and endogenous opioid peptides in the peripheral control of neuropathy-triggered heat pain. Sci. Rep. 2016, 6, 32799. [CrossRef]

63. Chaplan, S.R.; Bach, F.W.; Pogrel, J.W.; Chung, J.M.; Yaksh, T.L. Quantitative assessment of tactile allodynia in the rat paw. J. Neurosci. Methods 1994, 53, 55-63. [CrossRef] 
64. Hargreaves, K.; Dubner, R.; Brown, F.; Flores, C.; Joris, J. A new and sensitive method for measuring thermal nociception in cutaneous hyperalgesia. Pain 1988, 1, 77-88. [CrossRef] 